OPEN ACCESS

Edited by:

Norberto Perico,

Mario Negri Pharmacological

Research Institute, Italy

Reviewed by:

Susan J. Lewis,

University of Findlay,

United States

Jeffrey Lipman,

The University of Queensland,

Australia

*Correspondence:

Xiaoyang Lu

luxiaoyang@zju.edu.cn

Saiping Jiang

j5145@zju.edu.cn

Specialty section:

This article was submitted to

Renal Pharmacology,

a section of the journal

Frontiers in Pharmacology

Received: 14 January 2020

Accepted: 12 May 2020

Published: 29 May 2020

Citation:

Li L, LiX, Xia Y, Chu Y,

Zhong $H$, Li J, Liang $P$,

$B u Y$, Zhao R, Liao $Y$,

Yang P, Lu X and Jiang S (2020)

Recommendation of Antimicrobial

Dosing Optimization

During Continuous Renal

Replacement Therapy.

Front. Pharmacol. 11:786.

doi: 10.3389/fphar.2020.00786

\section{Recommendation of Antimicrobial Dosing Optimization During Continuous Renal Replacement Therapy}

\author{
$L u L i{ }^{1}$, Xin $L^{2}{ }^{2}$, Yanzhe Xia ${ }^{3}$, Yanqi Chu ${ }^{4}$, Haili Zhong ${ }^{5}$, Jia $L i^{3}$, Pei Liang ${ }^{6}$, Yishan $B u^{7}$, \\ Rui $Z_{\text {hao }}{ }^{8}$, Yun Liao ${ }^{9}$, Ping Yang ${ }^{1}$, Xiaoyang $L^{1 *}$ and Saiping Jiang ${ }^{1 *}$ \\ ${ }^{1}$ Department of Pharmacy, College of Medicine, The First Affiliated Hospital, Zhejiang University, Hangzhou, China, \\ 2 Department of Pharmacy, Second Hospital of Jilin University, Changchun, China, ${ }^{3}$ Department of Pharmacy, The First \\ Affiliated Hospital, Sun Yat-sen University, Guangzhou, China, ${ }^{4}$ Department of Pharmacy, Xuanwu Hospital of Capital \\ Medical University, Beijing, China, ${ }^{5}$ Department of Pharmacy, First Affiliated Hospital of Nanchang University, Nanchang, \\ China, ${ }^{6}$ Department of Pharmacy, Nanjing Drum Tower Hospital, Nanjing, China, ${ }^{7}$ Department of Pharmacy, Tianjin First \\ Central Hospital, Tianjin, China, ${ }^{8}$ School of Medicine, Sir Run Run Shaw Hospital, Zhejiang University, Hangzhou, China, \\ ${ }^{9}$ Department of Pharmacy, Tongren Hospital, Shanghai Jiao Tong University School of Medicine, Shanghai, China
}

Continuous Renal Replacement Therapy (CRRT) is more and more widely used in patients for various indications recent years. It is still intricate for clinicians to decide a suitable empiric antimicrobial dosing for patients receiving CRRT. Inappropriate doses of antimicrobial agents may lead to treatment failure or drug resistance of pathogens. CRRT factors, patient individual conditions and drug pharmacokinetics/pharmacodynamics are the main elements effecting the antimicrobial dosing adjustment. With the development of CRRT techniques, some antimicrobial dosing recommendations in earlier studies were no longer appropriate for clinical use now. Here, we reviewed the literatures involving in new progresses of antimicrobial dosages, and complied the updated empirical dosing strategies based on CRRT modalities and effluent flow rates. The following antimicrobial agents were included for review: flucloxacillin, piperacillin/tazobactam, ceftriaxone, ceftazidime/avibactam, cefepime, ceftolozane/tazobactam, sulbactam, meropenem, imipenem, panipenem, biapenem, ertapenem, doripenem, amikacin, ciprofloxacin, levofloxacin, moxifloxacin, clindamycin, azithromycin, tigecycline, polymyxin B, colistin, vancomycin, teicoplanin, linezolid, daptomycin, sulfamethoxazole/trimethoprim, fluconazole, voriconazole, posaconzole, caspofungin, micafungin, amphotericin B, acyclovir, ganciclovir, oseltamivir, and peramivir.

Keywords: antimicrobials, continuous renal replacement therapy, dosing optimization, pharmacokinetic, pharmacodynamics

\section{INTRODUCTION}

Infection is the one of the main causes of acute kidney injury (AKI), and renal replacement therapy is necessary for such patients. Sepsis causes more than half of all AKI (Bellomo et al., 2017), and therefore critically ill patients who receive renal replacement therapy often need to use antimicrobials at the same times. Continuous Renal Replacement Therapy (CRRT) is a therapy 
that replaces the normal blood-filtering function of the kidneys which continues for at least $24 \mathrm{~h}$. Compared with intermittent dialysis, CRRT is characterized by hemodynamic stability during treatment, and can maintain the fluid, electrolyte and acid alkaline balance in efficient and smooth manners (Deepa and Muralidhar, 2012). With the increasing use of CRRT, it is particularly important to understand the impact of CRRT on antimicrobial therapy (Bouchard et al., 2008). For patients using CRRT, there are many factors that may affect the antimicrobial pharmacokinetics (PK)/pharmacodynamics (PD), such as CRRT factors, patient individual differences, drug characteristics, and so on (Pea et al., 2007; Roberts et al., 2020). Inappropriate doses of antimicrobial agents may lead to increased adverse drug reactions, pathogen resistance, and clinical treatment failure. With the improvement of CRRT equipment, techniques, prescriptions (Macedo and Mehta, 2016), and as the PK/PD studies go on, previous studies do not reflect contemporary CRRT techniques (Trotman et al., 2005; Seyler et al., 2011) and prescriptions (Shaw and Mueller, 2017; Pistolesi et al., 2019) or include only a small number of agents (Hoff et al., 2019).

In the present work, we reviewed the studies and summarized the pharmacokinetic parameters of common antimicrobials, including antibacterial, antifungal and antiviral agents (Table 1). We classified these drugs (Table 2) and updated the recommendations for dose adjustment of antimicrobials for adults (Table 3) from the literatures (the majority of which were published from 2010 to March 2020) under different CRRT modalities and flow rates.

\section{CRRT FACTORS INFLUENCING THE PK/ PD OF ANTIMICROBIALS}

\section{CRRT Modalities}

CRRT mainly encompasses several therapeutic modalities (Tandukar and Palevsky, 2019). Continuous venous-venous hemodialysis (CVVHD), continuous venous-venous hemofiltration $(\mathrm{CVVH})$, and continuous venous-venous hemodiafiltration (CVVHDF) are the major modalities applied during therapy (Jiang et al., 2014). The modalities mentioned above involved three main techniques of clearance, including hemodialysis, hemofiltration, and hemodiafiltration (Tolwani, 2012). The clearance mechanism of hemodialysis is diffusion, which drives the solutes from a more concentrated to a less concentrated area. Drugs with small molecular weight ( $<500-1,000 \mathrm{Da})$ could be removed efficiently by hemodialysis. Dialysis fluid is required for hemodialysis. The clearance mechanism of hemofiltration is convection, which means the solutes move through a membrane with a pressure gradient. Drugs with larger molecular weight could be efficiently cleared by hemofiltration. Replacement fluid is required for hemofiltration. Hemodiafiltration combines diffusion and convection mechanisms. Solutes are removed by concentration gradient and pressure gradient. Both dialysis fluid and replacement fluid are required for hemodiafiltration. In general, drug removal may change in different CRRT methods, therefore we complied the dosing adjustment of antimicrobials basing on CRRT modalities in the present works.

\section{CRRT Membrane}

CRRT membranes vary in permeability, membrane composition, and contact area, which lead to the differences in drug clearance. The ability of drugs to pass through a filter membrane can be represented by the sieving coefficient (SC) and the saturation coefficient (SA). The SC and the SA indicate the ratio of solute concentration in ultrafiltrate (SC) or the dialysate (SA) to solute concentration in the blood (Wong et al., 2015). CRRT clearance can be calculated by SC/SA and effluent flow rates as follows: convention clearance $(\mathrm{ml} / \mathrm{min})=\mathrm{SC} \times$ ultrafiltrate flow rate $(\mathrm{ml} / \mathrm{min})$; diffusion clearance $=\mathrm{SA} \times$ dialysate flow rate $(\mathrm{ml} / \mathrm{min}$ ) (Pistolesi et al., 2019). SC or SA $=0$ represents all drugs cannot pass through the membranes, while $\mathrm{SC}$ or $\mathrm{SA}=1$ represents that all drugs can be filtered through the CRRT membrane.

Compared with intermittent hemodialysis filter membranes, CRRT membranes have increased pore size and can remove larger molecules effectively. Different CRRT membrane materials influence the clearance of antimicrobials. For example, polysulfone, polymethylmethacrylate and polyacrylonitrile membranes are typically used for CRRT. Among these membranes, polyacrylonitrile membranes have a hydrogen structure made of acrylonitrile/methallyl sulfonate copolymers, could absorb a large amount of proteins (Michikoshi et al., 2019). Compared with polysulfone, polyacrylonitrile filter membranes absorbed a large portion of the administered dose of antibiotics, such as gentamicin and tigecycline (Onichimowski et al., 2020a). Additionally, the surface area of the CRRT filters significantly increased from $0.6-0.9$ to $1.2-1.5 \mathrm{~m}^{2}$ over the past few years (Onichimowski et al., 2020a). A recent study demonstrated that patients receiving CVVHDF with $1.5 \mathrm{~m}^{2}$ AN69ST membranes required higher piperacillin/tazobactam doses than $0.9 \mathrm{~m}^{2}$ membranes (Ulldemolins et al., 2016). The increased membrane surface area might partially account for the augment of drug absorption. Membrane characteristics during CRRT should be taken into consideration while dosing adjustment. However, due to the limited studies on the antimicrobial absorptions of CRRT membranes, accurate dose recommendations are currently not available.

\section{Dilution Mode and Effluent Flow Rate}

Fluid can be infused before the filter (pre-dilution) or after the filter (post-dilution). In post-dilution mode, the plasm passes through the membrane directly, therefore the drug removal is associated with flow rate and sieving coefficient. In pre-dilution mode, plasm is diluted before filter leading to a decreased drug concentration before filtration, thus the clearance of drugs is relatively lower (Tandukar and Palevsky, 2019).

Effluent flow rate is the sum of dialysate and ultrafiltrate flow rates (Van Wert et al., 2010). KDIGO 2012 clinical practice guideline (Stevens and Levin, 2013) and KDOQI in 2013 (Palevsky et al., 2013) recommended that patients treated with CRRT receive an effluent flow rate of 20 to $25 \mathrm{ml} / \mathrm{kg} / \mathrm{h}$. However, 
TABLE 1 | Pharmacokinetic parameters of healthy volunteers.

\begin{tabular}{|c|c|c|c|c|c|c|c|}
\hline Antimicrobials & MW & $\begin{array}{l}\text { Protein } \\
\text { binding } \\
(\%)\end{array}$ & Vd & $\mathrm{T}_{1 / 2}(\mathrm{~h})$ & PK/PD characteristic & $\begin{array}{l}\text { PK/PD } \\
\text { target }\end{array}$ & excretion \\
\hline Flucloxacillin & 453 & 95 & $16.792 \mathrm{~L}$ & $0.5-1.1$ & time dependent & $\% \mathrm{~T}>\mathrm{MIC}$ & mainly through the kidney \\
\hline Piperacillin & 517 & $16-48$ & $0.24 \mathrm{~L} / \mathrm{kg}$ & 1 & time dependent & $\% \mathrm{~T}>\mathrm{MIC}$ & mainly through the kidney \\
\hline Tazobactam & 300 & - & $0.4 \mathrm{~L} / \mathrm{kg}$ & 1 & s & - & mainly through the kidney \\
\hline Ceftazidime & 636 & $<10$ & $0.24 \mathrm{~L} / \mathrm{kg}$ & 1.9 & time dependent & $\% \mathrm{~T}>\mathrm{MIC}$ & mainly through the kidney \\
\hline Avibactam & 265 & - & $0.31 \mathrm{~L} / \mathrm{kg}$ & 2.7 & - & - & mainly through the kidney \\
\hline Ceftriaxone & 554 & 85-95 & $5.8-13.5 \mathrm{~L}$ & 8 & time dependent & $\% \mathrm{~T}>\mathrm{MIC}$ & through kidney and biliary \\
\hline Cefepime & 571 & 20 & $18 \mathrm{~L}$ & 2.0 & time dependent & $\% \mathrm{~T}>\mathrm{MIC}$ & mainly through the kidney \\
\hline Ceftolozane & 667 & $16-21$ & $13.5 \mathrm{~L}$ & 3.1 & time dependent & $\% \mathrm{~T}>\mathrm{MIC}$ & kidney \\
\hline Sulbactam & 255 & 38 & $0.3 \mathrm{~L} / \mathrm{kg}$ & 1 & time dependent & $\% \mathrm{~T}>\mathrm{MIC}$ & mainly through the kidney \\
\hline Meropenem & 437.5 & 2 & $0.29 \mathrm{~L} / \mathrm{kg}$ & 1 & time dependent & $\% \mathrm{~T}>\mathrm{MIC}$ & mainly through the kidney \\
\hline Imipenem & 240 & $15-25$ & $0.27 \mathrm{~L} / \mathrm{kg}$ & 1 & time dependent & $\% \mathrm{~T}>\mathrm{MIC}$ & mainly through the kidney \\
\hline Panipenem & 339 & $6-7$ & $10.2 \pm 0.9 \mathrm{~L}$ & 1 & time dependent & $\% \mathrm{~T}>\mathrm{MIC}$ & kidney \\
\hline Biapenem & 350 & 3.7 & $11.75 \pm 3.86 \mathrm{~L}$ & 1 & time dependent & $\% \mathrm{~T}>\mathrm{MIC}$ & kidney \\
\hline Ertapenem & 475 & 95 & $0.12 \mathrm{~L}$ & 4 & time dependent & $\% \mathrm{~T}>\mathrm{MIC}$ & mainly through the kidney \\
\hline Doripenem & 420 & 8.1 & $16.8 \mathrm{~L}$ & 1 & time dependent & $\% \mathrm{~T}>\mathrm{MIC}$ & mainly through the kidney \\
\hline Amikacin & 585 & $0-10$ & $0.26 \mathrm{~L} / \mathrm{kg}$ & $2-3$ & concentration dependent & $\mathrm{C}_{\max } / \mathrm{MIC}$ & mainly through the kidney \\
\hline Ciprofloxacin & 331 & $20-40$ & $2.4 \mathrm{~L} / \mathrm{kg}$ & 4 & concentration dependent & $\mathrm{AUC}_{24} / \mathrm{MIC}$ & mainly through the kidney \\
\hline Levofloxacin & 361 & $24-38$ & $1.36 \mathrm{~L} / \mathrm{kg}$ & 7 & concentration dependent & $\mathrm{AUC}_{24} / \mathrm{MIC}$ & mainly through the kidney \\
\hline Moxifloxacin & 401 & $30-50$ & $2.2 \mathrm{~L} / \mathrm{kg}$ & $10-14$ & concentration dependent & $\mathrm{AUC}_{24} / \mathrm{MIC}$ & excreted by urine and feces \\
\hline Clindamycin & 425 & $85-94$ & $1.1 \mathrm{~L} / \mathrm{kg}$ & 2.4 & concentration dependent & $\mathrm{AUC}_{24} / \mathrm{MIC}$ & mainly excreted by biliary \\
\hline Azithromycin & 748 & $7-51$ & $33.3 \mathrm{~L} / \mathrm{kg}$ & 68 & time dependent, long PAE & $\mathrm{AUC}_{24} / \mathrm{MIC}$ & mainly excreted by biliary \\
\hline Tigecycline & 585 & $71-89$ & $7-9 \mathrm{~L} / \mathrm{kg}$ & 42 & time and concentration dependent & $\mathrm{AUC}_{24} / \mathrm{MIC}$ & excreted by urine and feces \\
\hline Polymyxin B & 1,189 & 60 & $0.07-0.2 \mathrm{~L} / \mathrm{kg}$ & 6 & concentration dependent, & $\mathrm{AUC}_{24} / \mathrm{MIC}$ & $\begin{array}{l}\text { mainly through non-renal } \\
\text { ways }\end{array}$ \\
\hline Colistin & 1,748 & $>50$ & $0.34 \mathrm{~L} / \mathrm{kg}$ & $2-3$ & concentration dependent & $\mathrm{AUC}_{24} / \mathrm{MIC}$ & mainly through the kidney \\
\hline Vancomycin & 1,448 & $10-55$ & $0.7 \mathrm{~L} / \mathrm{kg}$ & $4-6$ & time and concentration dependent & $\mathrm{AUC}_{24} / \mathrm{MIC}$ & mainly through the kidney \\
\hline Teicoplanin & 1,709 & 90-95 & $0.9-1.6 \mathrm{~L} / \mathrm{kg}$ & $70-100$ & time dependent, long PAE & $\mathrm{AUC}_{24} / \mathrm{MIC}$ & mainly through the kidney \\
\hline Linezolid & 337 & 31 & $40-50 \mathrm{~L}$ & 5 & time dependent, long PAE & $\mathrm{AUC}_{24} / \mathrm{MIC}$ & $\begin{array}{c}65 \% \text { is cleared by non-renal } \\
\text { ways }\end{array}$ \\
\hline Daptomycin & 1,620 & 92 & $0.1 \mathrm{~L} / \mathrm{kg}$ & $8-9$ & concentration dependent & $\mathrm{AUC}_{24} / \mathrm{MIC}$ & mainly through the kidney \\
\hline SMX/TMP & 290 & $\begin{array}{l}\text { SMX:70 } \\
\text { TMP:44 }\end{array}$ & $\begin{array}{l}\text { SMX:12-18 L; } \\
\text { TMP:100-120 L }\end{array}$ & $\begin{array}{l}\text { TMP:11 } \\
\text { SMX:9 }\end{array}$ & $\begin{array}{l}\text { the pharmacodynamic parameter } \\
\text { (concentration or time) has not been } \\
\text { determined (Brown, 2014) }\end{array}$ & - & mainly through the kidney \\
\hline Fluconazole & 306 & 10 & $50 \mathrm{~L}$ & $20-50$ & concentration dependent & $\mathrm{AUC}_{24} / \mathrm{MIC}$ & mainly through the kidney \\
\hline Voriconazole & 349 & 58 & $4.6 \mathrm{~L} / \mathrm{kg}$ & $\begin{array}{c}\text { Nonlinear } \\
\text { pharmacokinetics }\end{array}$ & time and concentration dependent & $\mathrm{AUC}_{24} / \mathrm{MIC}$ & $\begin{array}{l}\text { Less than } 2 \% \text { drug is } \\
\text { eliminated by kidney as } \\
\text { unchanged drug }\end{array}$ \\
\hline Posaconzole & 700 & $98-99$ & 226 295L & $20-66$ & time and concentration dependent & $\mathrm{AUC}_{24} / \mathrm{MIC}$ & mainly through the feces \\
\hline Caspofungin & 1,092 & 97 & $9.7 \mathrm{~L}$ & 13 & concentration dependent & $\mathrm{AUC}_{24} / \mathrm{MIC}$ & $\begin{array}{l}\text { metabolites were excreted by } \\
\text { urine }(41 \%) \text { and feces (35\%) }\end{array}$ \\
\hline Micafungin & 1,270 & $>99$ & $0.39 \mathrm{~L} / \mathrm{kg}$ & $14.0-17.2 \mathrm{~h}$ & concentration dependent & $\mathrm{AUC}_{24} / \mathrm{MIC}$ & mainly through the feces \\
\hline AMB & 924 & & $\begin{array}{l}\text { AMB: } 4 \text { L/kg; AMB } \\
\text { lipid complexes:0.1- } \\
\text { 0.4 L/kg }\end{array}$ & $\begin{array}{c}\text { AMB: } 24 ; \\
\text { AMB lipid } \\
\text { complexes: } 6.8\end{array}$ & concentration dependent & $\mathrm{C}_{\max } / \mathrm{MIC}$ & $\begin{array}{c}\text { Slowly excreted through the } \\
\text { kidney, about 2-5\% excreted } \\
\text { every day }\end{array}$ \\
\hline Acyclovir & 225 & $9-33$ & $0.7 \mathrm{~L} / \mathrm{kg}$ & $2.5-3.5$ & - & - & mainly through the kidney \\
\hline Ganciclovir & 255 & $1-2$ & $0.7 \mathrm{~L} / \mathrm{kg}$ & $3.5 \mathrm{~h}$ & - & - & mainly through the kidney \\
\hline Oseltamivir & 312 & 3 & 23-26 L/kg & $6-10$ & - & - & mainly through the kidney \\
\hline Peramivir & 346 & $<30$ & $12.56 \mathrm{~L}$ & 20 & - & - & mainly through the kidney \\
\hline
\end{tabular}

MW, Molecular weight; MIC, minimum inhibitory concentration; AUC, Area Under Curve.

TABLE 2 | Category of drugs in CRRT.

\begin{tabular}{|c|c|}
\hline Category & Antimicrobials \\
\hline $\begin{array}{l}\text { Drugs need } \\
\text { adjustments }\end{array}$ & $\begin{array}{l}\text { flucloxacillin, piperacillin/tazobactam, ceftazidime/avibactam, ceftolozane/tazobactam, sulbactam, cefepime, meropenem, imipenem, panipenan, } \\
\text { biaphenan, ertapenem, doripenem, amikacin, levofloxacin, ciprofloxacin, colistin, vancomycin, teicolanin, daptomycin, SMX/TMP, fluconazole, } \\
\text { acyclovir, ganciclovir, oseltamivir, peramivir }\end{array}$ \\
\hline $\begin{array}{l}\text { Drugs do not } \\
\text { need adjustments }\end{array}$ & ceftriaxone, moxifloxacin, clindamycin, azithromycin, tigecycline, polymyxin B, linezolid, voriconazole, posaconazole, caspofungin, micafungin, AMB \\
\hline
\end{tabular}


TABLE 3 | Recommendation of drug adjustment in CRRT.

\begin{tabular}{|c|c|c|c|}
\hline \multirow[t]{2}{*}{ Drug } & \multicolumn{3}{|c|}{ CRRT mode } \\
\hline & CVVH & CVVHD & CVVHDF \\
\hline Flucloxacillin & $\begin{array}{l}\text { Ultrafiltration rate: } 57 \pm 9 \mathrm{ml} / \mathrm{min} \\
4.0 \mathrm{~g} \text { q8h (Meyer et al., 2003) }\end{array}$ & - & - \\
\hline $\begin{array}{l}\text { Piperacillin/ } \\
\text { tazobactam }\end{array}$ & $\begin{array}{l}\text { Ultrafiltration rate: } 30 \mathrm{ml} / \mathrm{kg} / \mathrm{h} \\
\text { Loading dose: } 4.5 \mathrm{~g} \\
\text { Maintenance dose: } 500 \mathrm{mg} / \mathrm{h} \text { (Roger et al., 2017a) } \\
\text { Ultrafiltration rate: } 1,000 \mathrm{ml} / \mathrm{h} \text { to } 2,150 \mathrm{ml} / \mathrm{h} \\
\text { Dose: } 4.5 \mathrm{~g} \text { q6h (Asin-Prieto et al., 2014) }\end{array}$ & $\begin{array}{l}\text { Dialysate rate: } 23 \pm 9 \mathrm{ml} / \mathrm{kg} / \mathrm{h} \\
4.5 \mathrm{~g} \text { q6h or higher (for less susceptible } \\
\text { pathogens) (Seyler et al., 2011) }\end{array}$ & $\begin{array}{l}\text { Ultrafiltration rate: } 15 \mathrm{ml} / \mathrm{kg} / \mathrm{h} \\
\text { Dialysate flow rate: } 15 \mathrm{ml} / \mathrm{kg} / \mathrm{h} \\
\text { Loading dose: } 4.5 \mathrm{~g} \\
\text { Maintenance dose: } 500 \mathrm{mg} / \mathrm{h} \text { (Roger et al., } \\
2017 \mathrm{a} \text { ) } \\
\text { Ultrafiltration rate: } 22 \pm 12 \mathrm{ml} / \mathrm{kg} / \mathrm{h} \\
\text { Dialysate rate: } 23 \pm 9 \mathrm{ml} / \mathrm{kg} / \mathrm{h} \\
4.5 \mathrm{~g} \text { q6h or higher (for less susceptible } \\
\text { pathogens) (Seyler et al., } 2011 \text { ) }\end{array}$ \\
\hline Ceftriaxone & No change & No change & No change \\
\hline $\begin{array}{l}\text { Ceftazidime/ } \\
\text { Avibactam }\end{array}$ & - & - & $\begin{array}{l}\text { Ultrafiltration rate: } 0.25 \mathrm{~L} / \mathrm{h} \\
\text { Dialysate rate: } 1.5 \mathrm{~L} / \mathrm{h} \\
2.5 \mathrm{~g} \text { q8h (Soukup et al., 2019) }\end{array}$ \\
\hline Cefepime & $\begin{array}{l}\text { Ultrafiltration rate: } \leq 1,000 \mathrm{ml} / \mathrm{h} \\
1 \mathrm{~g} \text { q8h } \\
\text { Ultrafiltration rate: } \geq 1,500 \mathrm{ml} / \mathrm{h} \\
2 \mathrm{~g} \text { q8h or } 1 \mathrm{~g} \text { q6h (Carlier et al., 2015) } \\
\text { Ultrafiltration rate: } 30.1 \pm 5.4 \mathrm{ml} / \mathrm{kg} / \mathrm{h} \\
2 \mathrm{~g} \text { q8h extended infusion (Philpott et al., 2019) }\end{array}$ & $\begin{array}{l}\text { Dialysate rate: } 20-25 \mathrm{ml} / \mathrm{kg} / \mathrm{h} \\
\text { Loading dose: } 2 \mathrm{~g} \\
\text { Maintenance dose: } 1.5-1.75 \mathrm{~g} \text { q8h (Chaijamorn } \\
\text { et al., 2018) } \\
\text { Dialysate rate: } 30.1 \pm 5.4 \mathrm{ml} / \mathrm{kg} / \mathrm{h} \\
2 \mathrm{~g} \text { q8h extended infusion (Philpott et al., 2019) }\end{array}$ & $\begin{array}{l}\text { Combined flow rate: } \leq 1,000 \mathrm{ml} / \mathrm{h} \\
1 \mathrm{~g} \text { q8h } \\
\text { Combined flow rate: } \geq 1,500 \mathrm{ml} / \mathrm{h} \\
2 \mathrm{~g} \text { q8h or } 1 \mathrm{~g} \text { q6h (Carlier et al., 2015) }\end{array}$ \\
\hline $\begin{array}{l}\text { Ceftolozane/ } \\
\text { tazobactam }\end{array}$ & $\begin{array}{l}\text { Ultrafiltration rate: } 20-25 \mathrm{ml} / \mathrm{kg} / \mathrm{h} \text { (pre or post- } \\
\text { dilution), and } 35 \mathrm{ml} / \mathrm{kg} / \mathrm{h} \text { (pre-dilution) } \\
\text { Loading dose: } 750 \mathrm{mg} \\
\text { Maintenance dose: } 1.5 \mathrm{~g} \text { continuous infusion q24h } \\
\text { Ultrafiltration rate: } 35 \mathrm{ml} / \mathrm{kg} / \mathrm{h} \\
\text { Loading dose: } 1.5 \mathrm{~g} \\
\text { Maintenance dose: } 2.25 \mathrm{~g} \text { continuous infusion } \\
\text { q24h; } \\
\text { Ultrafiltration rate: } 20-35 \mathrm{ml} / \mathrm{kg} / \mathrm{h} \text { (pre-dilution), } \\
\text { and } 20 \mathrm{ml} / \mathrm{kg} / \mathrm{h} \text { (post-dilution) } \\
750 \mathrm{mg} \text { q8h intermittent infusion } \\
\text { Ultrafiltration rate: } 25-35 \mathrm{~m} / / \mathrm{kg} / \mathrm{h} \text { (post-dilution) } \\
1.5 \mathrm{~g} \text { q8h intermittent infusion (Chaijamorn et al., } \\
2017 \text { ) }\end{array}$ & $\begin{array}{l}\text { Dialysate rate: } 20-25 \mathrm{ml} / \mathrm{kg} / \mathrm{h} \\
\text { Loading dose: } 750 \mathrm{mg} \\
\text { Maintenance dose: } 1.5 \mathrm{~g} \text { continuous infusion q24h } \\
\text { or } \\
750 \mathrm{mg} \text { q8h intermittent infusion } \\
\text { Dialysate rate: } 35 \mathrm{ml} / \mathrm{kg} / \mathrm{h} \\
\text { Loading dose: } 1.5 \mathrm{~g} \\
\text { Maintenance dose: } 2.25 \mathrm{~g} \text { continuous infusion } \\
\text { q24h or } \\
1.5 \mathrm{~g} \text { q8h intermittent infusion } \\
\text { (Chaijamorn et al., 2017) }\end{array}$ & $\begin{array}{l}\text { Combined flow rate: } 1,000-1,500 \mathrm{ml} / \mathrm{h} \\
\text { Loading dose: } 3 \mathrm{~g} \\
\text { Maintenance dose: } 0.75 \mathrm{~g} \text { q8h (Sime et al., } \\
\text { 2019) } \\
\text { Ultrafiltration rate: } 2 \mathrm{~L} / \mathrm{h} \text { or } 1 \mathrm{~L} / \mathrm{h} \\
\text { Dialysate rate: } 2 \mathrm{~L} / \mathrm{h} \\
3 \mathrm{~g} \text { q8h continuous infusion (Aguilar et al., } \\
\text { 2019; Mahmoud et al., 2020) }\end{array}$ \\
\hline Sulbactam & $\begin{array}{l}\text { Ultrafiltration rate: } 30 \text { ml/h/kg } \\
1 \mathrm{~g} \text { q8h (Gao et al., 2016) }\end{array}$ & $\begin{array}{l}\text { Dialysate rate: } 1 \mathrm{~L} / \mathrm{h} \\
1 \mathrm{~g} \text { q8h (Trotman et al., 2005) }\end{array}$ & $\begin{array}{l}\text { Combined flow rate: } 1 \mathrm{~L} / \mathrm{h} \\
\text { 1g q8h (Trotman et al., 2005) }\end{array}$ \\
\hline Meropenem & $\begin{array}{l}\text { Ultrafiltration rate: } 22 \pm 12 \mathrm{ml} / \mathrm{kg} / \mathrm{h} \\
1 \mathrm{~g} \text { q12h (MIC } \leq 1 \mathrm{mg} / \mathrm{L} \text { ) (Seyler et al., 2011) } \\
\text { Ultrafiltration rate: } \geq 4 \mathrm{~L} / \mathrm{h} \\
1 \mathrm{~g} \text { q8h (Bilgrami et al., 2010) } \\
\text { Ultrafiltration rate: } 35 \mathrm{ml} / \mathrm{kg} / \mathrm{h} \\
1 \mathrm{~g} \text { q8h } 1 \mathrm{~h} \text { infusion (Onichimowski et al., 2020b) }\end{array}$ & $\begin{array}{l}\text { Dialysate rate: } 20-35 \text { ml/kg/h } \\
2 \text { g q12 h; or Loading dose:1 g, Maintenance } \\
\text { dose:500 mg q8 h; or Loading dose: } 1 \text { g LD, } \\
\text { Maintenance dose:1 g q12 h (Shaw and Mueller, } \\
2017 \text { ) } \\
\text { Dialysate rate: } 35 \text { ml/kg/h } \\
1 \mathrm{~g} \text { q8h } 1 \mathrm{~h} \text { infusion (Onichimowski et al., 2020b) } \\
\text { Dialysate rate: } 0.7-1 \mathrm{~L} / \mathrm{h} \\
0.25 \text { q24h for } \mathrm{MlC} \leq 2 \mathrm{mg} / \mathrm{L} \\
>0.5 \mathrm{~g} \text { q8h for } \mathrm{MIC}=16 \mathrm{mg} / \mathrm{L} \text { (Kawano et al., } \\
2015 \text { ) } \\
\text { Dialysate rate: } 30 \mathrm{ml} / \mathrm{kg} / \mathrm{h} \\
1 \mathrm{~g} \text { q8h or } 2 \mathrm{~g} \text { q8h or } 3 \mathrm{~g} \text { continuous infusion } \\
\text { q24h (Grensemann et al., 2020) }\end{array}$ & $\begin{array}{l}\text { Ultrafiltration rate: } 22 \pm 12 \mathrm{ml} / \mathrm{kg} / \mathrm{h} \\
\text { Dialysate rate: } 23 \pm 9 \mathrm{ml} / \mathrm{kg} / \mathrm{h} \\
1 \mathrm{~g} \text { q12h (MIC } \leq 1 \mathrm{mg} / \mathrm{L})(\text { Seyler et al., 2011) } \\
\text { Ultrafiltration rate: } 2 \mathrm{~L} / \mathrm{h} \\
\text { Dialysate rate: } 1 \mathrm{~L} / \mathrm{h} \\
500 \mathrm{mg} \text { q } 8 \mathrm{~h}(\mathrm{MIC} \leq 4 \mathrm{mg} / \mathrm{L}) \text { (Varghese et al., } \\
2015) \\
\text { Ultrafiltration rate: } 1.5-2 \mathrm{~L} / \mathrm{h} \\
\text { Dialysate rate: } 1-1.5 \mathrm{~L} / \mathrm{h} \\
1 \mathrm{~g} \text { q } 8 \mathrm{~h}\end{array}$ \\
\hline Imipenem & $\begin{array}{l}\text { Ultrafiltration rate: } 52 \pm 14 \mathrm{ml} / \mathrm{kg} / \mathrm{h} \\
1.0 \mathrm{~g} \text { q6h } \\
\text { Ultrafiltration rate: } 20 \text { or } 37 \mathrm{ml} / \mathrm{kg} / \mathrm{h} \\
0.5 \mathrm{~g} \text { q6h for } \mathrm{MIC} \leq 2 \mathrm{mg} / \mathrm{L}, 1.0 \mathrm{~g} \text { q6h for MIC 4- } \\
16 \mathrm{mg} / \mathrm{L} \text { (Li and Xie, 2019) }\end{array}$ & $\begin{array}{l}\text { Dialysate rate: } 20 \text { or } 37 \mathrm{ml} / \mathrm{kg} / \mathrm{h} \\
0.5 \mathrm{~g} \text { q6h for } \mathrm{MIC} \leq 2 \mathrm{mg} / \mathrm{L}, 1.0 \mathrm{~g} \text { q6h for MIC 4- } \\
16 \mathrm{mg} / \mathrm{L} \text { (Li and Xie, 2019) }\end{array}$ & $\begin{array}{l}\text { Combined flow rate: } 20 \text { or } 37 \mathrm{ml} / \mathrm{kg} / \mathrm{h} \\
0.5 \mathrm{~g} \text { q6h for } \mathrm{MIC} \leq 2 \mathrm{mg} / \mathrm{L}, 1.0 \mathrm{~g} \text { q6h for MIC } \\
\text { 4-16 mg/L (Li and Xie, 2019) }\end{array}$ \\
\hline Panipenan & $\begin{array}{l}\text { CLtot }(\mathrm{ml} / \mathrm{min})=(1.2 \text { creatinine clearance }+66.5)+ \\
\mathrm{ml} / \mathrm{min}, 0.5 \mathrm{q} 8 \mathrm{~h} \text { or } 1.0 \mathrm{~g} \mathrm{q} 12 \mathrm{~h} ; 120 \leq \text { CLtot } \leq 160 \mathrm{n}\end{array}$ & $\begin{array}{l}+0.86 \text { (dialysate rate }+ \text { ultrafiltration rate) CLtot }<80 \mathrm{ml} / \\
\mathrm{nl} / \mathrm{min}, 0.5 \mathrm{~g} \text { q6h or } 1.0 \mathrm{~g} \text { q8h (Hayakawa et al., 2006) }\end{array}$ & /min, 0.5 q12h or $1.0 \mathrm{~g}$ q15h; $80 \leq$ CLtot $\leq 120$ \\
\hline Biapenan & - & - & $\begin{array}{l}\text { Ultrafiltration rate: } 1,000 \mathrm{ml} / \mathrm{h} \\
\text { Dialysate rate: } 500 \mathrm{ml} / \mathrm{h} \\
300 \mathrm{mg} \text { q6h (Akashita et al., 2015) }\end{array}$ \\
\hline
\end{tabular}


TABLE 3 | Continued

\begin{tabular}{|c|c|c|c|}
\hline \multirow[t]{2}{*}{ Drug } & \multicolumn{3}{|c|}{ CRRT mode } \\
\hline & CVVH & CVVHD & CVVHDF \\
\hline Ertapenem & - & $\begin{array}{l}\text { Dialysate rate: } 1-3 \mathrm{~L} / \mathrm{h} \\
500 \mathrm{mg} \text { q24h, } 750 \mathrm{mg} \text { q24h, } 500 \mathrm{mg} \text { q12h, or } \\
1,000 \mathrm{mg} \text { q24h (Eyler et al., 2014) }\end{array}$ & $\begin{array}{l}\text { Combined flow rate: } 36-51 \mathrm{ml} / \mathrm{h} / \mathrm{kg} \\
500 \mathrm{mg} \text { q24h, } 750 \mathrm{mg} \text { q24h, } 500 \text { mg q12h, } \\
\text { or 1,000 mg q24h (Eyler et al., 2014) }\end{array}$ \\
\hline Doripenem & $\begin{array}{l}\text { Ultrafiltration rate: } 1,900-3,250 \text { ml/h } \\
1 \mathrm{~g} \text { q8h (Vossen et al., 2015) }\end{array}$ & $\begin{array}{l}\text { Dialysate rate: } 2 \text { L/h } \\
1 \mathrm{~g} \text { q8h (Vossen et al., 2015) }\end{array}$ & $\begin{array}{l}\text { Combined flow rate: } 1,500-2,800 \mathrm{ml} / \mathrm{h} \\
1 \mathrm{~g} \text { q8h (Vossen et al., 2015) }\end{array}$ \\
\hline Amikacin & $\begin{array}{l}\text { Ultrafiltration rate: } 30 \text { ml/kg/h } \\
25 \text { mg/kg q48h (Roger et al., 2016b) }\end{array}$ & $\begin{array}{l}\text { Exact dose cannot be predicted (Lam and Bauer, } \\
\text { 2013) }\end{array}$ & $\begin{array}{l}\text { Combined flow rate: } 30 \text { ml/kg/h } \\
25 \text { mg/kg q48h (Roger et al., 2016b) }\end{array}$ \\
\hline Levofloxacin & $\begin{array}{l}\text { Ultrafiltration rate: } 14-23 \text { ml/min } \\
250 \text { mg q24h (Malone et al., 2001) }\end{array}$ & $\begin{array}{l}\text { Not suitable as monotherapy to treat gram- } \\
\text { negative infections (Shaw and Mueller, 2017) }\end{array}$ & $\begin{array}{l}\text { Dialysate rate: } 0.8-1.5 \mathrm{ml} / \mathrm{min} \text {, Ultrafiltration } \\
\text { rate: } 9-23 \mathrm{ml} / \mathrm{min} \\
250 \mathrm{mg} \text { q24h (Malone et al., 2001) }\end{array}$ \\
\hline Ciprofloxacin & $\begin{array}{l}\text { Ultrafiltration rate: } 30 \text { ml/kg/h } \\
400 \text { mg q8h (Roger et al., 2016a) }\end{array}$ & $\begin{array}{l}\text { Dialysate rate: } 3 \text { L/h } \\
200 \text { mg q8h (Wallis et al., 2001) }\end{array}$ & $\begin{array}{l}\text { Dialysate rate: } 2 \mathrm{~L} / \mathrm{h} \\
\text { Ultrafiltration rate: } 2 \mathrm{~L} / \mathrm{h} \\
400 \mathrm{mg} \text { q12h (MIC } \leq 0.5 \mathrm{mg} / \mathrm{L} \text { ) (Spooner et al., } \\
2011 \text { ) } \\
\text { Ultrafiltration rate: } 15 \mathrm{ml} / \mathrm{kg} / \mathrm{h} \text { dialysate rate: } 15 \\
\mathrm{ml} / \mathrm{kg} / \mathrm{h} \\
400 \mathrm{mg} \text { q8h (Roger et al., } 2016 \mathrm{a})\end{array}$ \\
\hline Polymyxin B & No change & No change & No change \\
\hline CMS & $\begin{array}{l}\text { Ultrafiltration rate: } 35 \mathrm{ml} / \mathrm{kg} / \mathrm{h} \\
\text { Loading dose: } 9 \text { million } U \\
\text { Maintenance dose: } 4.5 \text { million U tid (Honore et al., } \\
\text { 2014; Spapen et al., 2019) }\end{array}$ & $\begin{array}{l}\text { Dialysate rate: } 42 \mathrm{ml} / \mathrm{min} \\
\text { A loading CBA dose: } \mathrm{C}_{\mathrm{ss}, \text { avg }}(\mathrm{mg} / \mathrm{L}) \times 2.0 \times \text { body } \\
\text { weight }(\mathrm{kg}) \\
\text { Maintenance dose: } \\
192 \mathrm{mg} \times \mathrm{C}_{\mathrm{ss}, \text { avg }}(\mathrm{mg} / \mathrm{L}) \text { q8-12h (Garonzik et al., } \\
2011) \\
\text { Dialysate rate: } 1-1.5 \mathrm{~L} / \mathrm{h} \\
\text { Loading dose: } 9 \text { million } \mathrm{U} \\
\text { Maintenance dose:4.5 million } \mathrm{U} \text { q12h (Leuppi- } \\
\text { Taegtmeyer et al., } 2019)\end{array}$ & $\begin{array}{l}\text { Ultrafiltration rate: } 0.5-0.9 \mathrm{~L} / \mathrm{h} \text {, Dialysate rate: } \\
1.0-1.5 \mathrm{~L} / \mathrm{h} \\
\text { Loading dose: CMS } 12 \text { million U } \\
\text { Maintenance dose: } 6.5-7.5 \text { million U q12h } \\
\text { (Karaiskos et al., 2016) }\end{array}$ \\
\hline Clindamycin & No change & No change & No change \\
\hline Azithromycin & No change & No change & No change \\
\hline Tigecycline & No change & No change & No change \\
\hline Vancomycin & $\begin{array}{l}\text { Ultrafiltration rate: } 30-40 \text { ml/kg/h } \\
400-650 \text { mg q12h (Li et al., 2020) }\end{array}$ & $\begin{array}{l}\text { Dialysate rate: } 25 \mathrm{ml} / \mathrm{kg} / \mathrm{h} \\
\text { Loading dose: } 1.5 \mathrm{~g} \\
\text { Maintenance dose: } 500 \mathrm{mg} \text { q8h (van de Vijsel } \\
\text { et al., 2010) }\end{array}$ & $\begin{array}{l}\text { Loading dose: } 15-20 \text { mg/kg } \\
\text { Maintenance dose: } 500 \text { mg (7.5-10 mg/kg) } \\
\text { q24h (Matsumoto et al., 2013) }\end{array}$ \\
\hline Teicolanin & $\begin{array}{l}\text { Loading dose: 1,200 mg } \\
\text { Maintenance dose: 600-1,800 mg q24h } \\
\text { (Bellmann et al., 2010) }\end{array}$ & $\begin{array}{l}\text { Dialysate rate: } 16 \mathrm{ml} / \mathrm{min} \\
\text { Loading dose: } 800 \mathrm{mg} \\
\text { Maintenance dose: } 400 \mathrm{mg} \text { q48-72h (Wolter } \\
\text { et al., 1994) }\end{array}$ & - \\
\hline Daptomycin & - & $\begin{array}{l}\text { Dialysate rate }>30 \text { ml/kg/h } \\
6 \mathrm{mg} / \mathrm{kg} \text { q24h (Corti et al., 2013; Xie et al., 2020) }\end{array}$ & $\begin{array}{l}\text { Combined flow rate }>30 \text { ml/kg/h } \\
\text { 6-8 mg/kg q24h (Corti et al., 2013; Xu et al., } \\
\text { 2017; Xie et al., 2020) }\end{array}$ \\
\hline Linezolid & No change & No change & No change \\
\hline SMX/TMP & $\begin{array}{l}\text { Ultrafiltration rate: } 1,2,3,6 \mathrm{~L} / \mathrm{h} \\
\text { TMP } 10 \text { mg/kg/day divided q12h (Kesner et al., } \\
\text { 2014) }\end{array}$ & $\begin{array}{l}\text { Dialysate rate: } 1,2,3,6 \mathrm{~L} / \mathrm{h} \\
\text { TMP } 10 \mathrm{mg} / \mathrm{kg} / \text { day divided q12h (Kesner et al., } \\
\text { 2014) }\end{array}$ & - \\
\hline Fluconazole & $\begin{array}{l}\text { Ultrafiltration rate: } 1 \mathrm{~L} / \mathrm{h} \\
400 \mathrm{mg} \text { q24h (Trotman et al., 2005) } \\
\text { Ultrafiltration rate: } 2.4-3.2 \mathrm{~L} / \mathrm{h} \\
\text { Loading dose: } 12 \mathrm{mg} / \mathrm{kg} \text { lean body weight } \\
\text { Maintenance dose: } 6 \text { mg/kg lean body weight } \\
\text { q24h (Lopez and Phillips, 2014) }\end{array}$ & $\begin{array}{l}\text { Dialysate flow rate: } 1 \mathrm{~L} / \mathrm{h} \\
800 \mathrm{mg} \text { q24h (Trotman et al., 2005) } \\
\text { Dialysate flow rate: } 4 \mathrm{~L} / \mathrm{h} \\
\text { Loading dose: } 900 \mathrm{mg} \\
\text { Maintenance dose: } 600 \mathrm{mg} \text { q12h (Oualha et al., } \\
\text { 2019) }\end{array}$ & $\begin{array}{l}\text { Ultrafiltration rate: } 2 \mathrm{~L} / \mathrm{h} \\
\text { Dialysate flow rate: } 1 \mathrm{~L} / \mathrm{h} \\
400 \mathrm{mg} \text { q12h (Patel et al., 2011) }\end{array}$ \\
\hline Voriconazole & No change & No change & No change \\
\hline Posaconazole & No change & No change & No change \\
\hline Caspofungin & No change & No change & No change \\
\hline Micafungin & No change & No change & No change \\
\hline AMB & No change & No change & No change \\
\hline Acyclovir & $\begin{array}{l}\text { Ultrafiltration rate: } 1 \mathrm{~L} / \mathrm{h} \\
5-7.5 \mathrm{mg} / \mathrm{kg} \text { q24h (Trotman et al., 2005) }\end{array}$ & $\begin{array}{l}\text { Dialysate flow rate: } 1 \mathrm{~L} / \mathrm{h} \\
5-7.5 \mathrm{mg} / \mathrm{kg} \text { q24h (Trotman et al., 2005) }\end{array}$ & $\begin{array}{l}\text { Ultrafiltration rate: } 1 \mathrm{~L} / \mathrm{h} \\
\text { Dialysate flow rate: } 1 \mathrm{~L} / \mathrm{h} \\
5-7.5 \mathrm{mg} / \mathrm{kg} \text { q24h (Trotman et al., 2005) }\end{array}$ \\
\hline
\end{tabular}

(Continued) 
TABLE 3 | Continued

\begin{tabular}{|c|c|c|c|}
\hline \multirow[t]{2}{*}{ Drug } & \multicolumn{3}{|c|}{ CRRT mode } \\
\hline & CVVH & CVVHD & CVVHDF \\
\hline Ganciclovir & - & $\begin{array}{l}\text { Dialysate flow rate: } 1 \mathrm{~L} / \mathrm{h} \\
5 \mathrm{mg} / \mathrm{kg} \text { q48h (Bastien et al., 1994) }\end{array}$ & $\begin{array}{l}\text { Ultrafiltration rate: } 1 \mathrm{~L} / \mathrm{h} \\
\text { Dialysate flow rate: } 1 \mathrm{~L} / \mathrm{h} \\
2.5 \mathrm{mg} / \mathrm{kg} \text { q24h (Horvatits et al., 2014) }\end{array}$ \\
\hline Oseltamivir & - & $\begin{array}{l}\text { Dialysate flow rate: } 30.8 \pm 3.57 \mathrm{ml} / \mathrm{kg} / \mathrm{h} \\
\text { less than } 150 \mathrm{mg} \mathrm{q} 12 \mathrm{~h} \text { (Eyler et al., 2012) }\end{array}$ & $\begin{array}{l}\text { Ultrafiltration rate: } 1.5 \mathrm{~L} / \mathrm{h} \\
\text { Dialysate flow rate: } 1.5 \mathrm{~L} / \mathrm{h} \\
\text { less than } 150 \mathrm{mg} \text { or } 75 \mathrm{mg} \text { q12h (Lemaitre } \\
\text { et al., 2012) }\end{array}$ \\
\hline Peramivir & $\begin{array}{l}\text { Ultrafiltration rate: } 48 \text { ml/kg/h } \\
600 \text { mg q24h (Scheetz et al., 2011) }\end{array}$ & & $\begin{array}{l}\text { Ultrafiltration rate: } 1 \mathrm{~L} / \mathrm{h} \\
\text { Dialysate flow rate: } 1 \mathrm{~L} / \mathrm{h} \\
600 \text { mg q24h (Bazan et al., 2010) }\end{array}$ \\
\hline
\end{tabular}

CLtot, total clearance; CBA, colistin base activity.

CRRT dosing remains highly variable in practice despite the national guidelines (Tandukar and Palevsky, 2019). Several studies have demonstrated that higher flow rate increases the clearance of some drugs, and may need higher antimicrobial dose regimens (Ohchi et al., 2011; Jamal et al., 2014; Boucher et al., 2016; Chaijamorn et al., 2017; Kohama et al., 2017). Although simply adjusting doses to effluent rate is insufficient to assure reaching antibiotic exposure goals due to the variability of critically ill patients (Roberts et al., 2012; Jang et al., 2019). It is still important and necessary to consider the effluent flow rate of CRRT for antimicrobial agents dosing strategies (Roberts et al., 2015).

\section{ANTIMICROBIALS DOSING STRATEGIES DURING CRRT}

The ability of drugs removal in CRRT can be affected by their own properties. Molecular weight, protein binding, drug elimination pathways and volume of distribution (Vd) are the regarded as most important factors to affect PK parameters during CRRT. CRRT can remove larger molecule drugs than low flux hemodialysis. Most of the antimicrobial drugs have a molecular weight $<750 \mathrm{Da}$, while some antimicrobials with larger molecular weight can be effectively filtered under hemofiltration and hemodiafiltration modes. Drugs bind to protein would result in the formation of large molecular compounds which are difficult to remove by CRRT. However, some studies showed that some antimicrobials with high protein binding have high SC or SA (Stevenson et al., 2008). This may due to the altered clinical conditions (e.g., blood pH, hypoproteinemia, drug competition) in critically ill patients receiving CRRT. CRRT significantly increase the clearance rates of drugs mainly eliminated by the kidney. Considering the body fluid removal, CRRT may also increase the clearance rate of drugs eliminated by other organs to some extent. Drugs with small Vd are usually hydrophilic drugs, which are generally eliminated by renal. Drugs with large Vd are usually lipophilic drugs, which are typically eliminated by other organs. These drugs are less likely to be influenced by renal replacement therapy. However, CRRT act as a continuous therapy may increase the drug redistribution from tissues to vascular, and may have greater impacts on clearance of drugs with large $\mathrm{Vd}$.

Moreover, $\mathrm{PK} / \mathrm{PD}$ goals are key indicators to evaluate the efficacy of drug dosage regimens during CRRT. In simple terms, antimicrobials could be classified into time-dependent antibiotics and concentration-dependent drugs. The index associated with time-dependent action is time above the MIC (\% $\mathrm{T}>\mathrm{MIC})$, while the index associated with concentrationdependent action are the ratio of peak concentration and MIC $\left(\mathrm{C}_{\max } / \mathrm{MIC}\right)$ and the ratio of 24 -h area under the curve and MIC $\left(\mathrm{AUC}_{24} / \mathrm{MIC}\right)$ (Mueller et al., 2004). One-size-fits-all dosing in critically ill subjects receiving CRRT might be improper (Afshartous et al., 2014). However, we tried to make dosing recommendation for adult patients according to CRRT modalities and flow rates in the present work. The search strategy for the literature selection used was: (drug name) AND (continuous renal replacement therapy OR hemodialysis OR hemofiltration OR hemodiafiltration OR CVVH OR CVVHD OR CVVHDF).

\section{Antimicrobials Which Are Required for Dosing Adjustment Flucloxacillin}

Flucloxacillin is mainly eliminated by the kidney. Flucloxacillin has a low SC (mean SC 0.3) under CVVH. It could be explained by the high protein binding rate of flucloxacillin (Bouman et al., 2006). Despite of the low SC, serum levels of flucloxacillin significantly decreased after ultrafiltration. This may be related to the adsorption of polyamide membrane (Meyer et al., 2003). A flucloxacillin regimen of $4.0 \mathrm{~g} \mathrm{q} 8 \mathrm{~h}$ seems to be appropriate for most of the methicillin-susceptible Gram-positive infection treatment during CVVH. The recommended dose of flucloxacillin during $\mathrm{CVVH}$ is higher than usual dose (16 g daily).

\section{Piperacillin/Tazobactam}

Both piperacillin and tazobactam are eliminated via the kidney by glomerular filtration and tubular secretion. Piperacillin/ tazobactam can be removed in different kinds of CRRT modalities. Higher but not significant piperacillin clearance was reported in patients receiving CVVHDF compared with 
CVVH (Roger et al., 2017a). Meanwhile, no significant impact between CVVHD and CVVHDF on the piperacillin/tazobactam PK parameters (Seyler et al., 2011). Earlier studies indicated that $2.25 \mathrm{~g}$ q6h to $3.375 \mathrm{~g}$ q6-8h was suitable for CVVH, and $3.375 \mathrm{~g}$ q6h was appropriate for CVVHD and CVVHDF (Trotman et al., 2005; Heintz et al., 2009). A population pharmacokinetics study indicated that piperacillin/tazobactam $4.5 \mathrm{~g}$ q6h provided high probability of target attainment under CVVH mode (Asin-Prieto et al., 2014). Continuous infusion of piperacillin/tazobactam could significantly improve PK targetS attainment (Jamal et al., 2015; Shotwell et al., 2016; Roger et al., 2017a; Richter et al., 2019). A high piperacillin/tazobactam dose (18 g daily) using continuous infusion is recommended to treat less susceptible pathogens or patients with septic shock during CRRT.

\section{Ceftazidime/Avibactam}

Ceftazidime/avibactam is a novel $\beta$-lactam $/ \beta$-lactamase inhibitor combination used in multidrug-resistant gram-negative infections. Limited data were available for ceftazidime/ avibactam dosing during CRRT. Both ceftazidime and avibactam could be removed by $\mathrm{CVVH}$, but the dosing strategy during CVVH was not clear (Wenzler et al., 2017). A case report found that $2.5 \mathrm{~g}$ infused over $2 \mathrm{~h}$ q8h was appropriate during CVVHDF (Soukup et al., 2019). According to the limited available evidence, a usual dose regimen is recommended, while further study is urgently needed.

\section{Cefepime}

About $85 \%$ of cefepime is excreted from urine as unchanged drug. Cefepime can be removed by CRRT. Earlier studies recommended 1-2 g q12h cefepime under CVVH and $1 \mathrm{~g}$ q8h or $2 \mathrm{~g}$ q12h under CVVHD or CVVHDF (Trotman et al., 2005; Heintz et al., 2009). A recent study showed that the variability in cefepime PK parameters during CVVH or CVVHDF. Monte Carlo methods indicated that $2 \mathrm{~g}$ q8h was suitable for high flow rate $(>1.5 \mathrm{~L} / \mathrm{h})$, while $1 \mathrm{~g} \mathrm{q} 8 \mathrm{~h}$ was appropriate for low flow rate $(\leq 1 \mathrm{~L} / \mathrm{h}$ ) under CVVH or CVVHDF (Carlier et al., 2015). The optimal dosing should be adjusted based on CRRT modalities, MICs and flow rates (Chaijamorn et al., 2018). Extended infusion of cefepime improves the PK/PD target attainment (100\% fT > $\mathrm{MIC}_{8}$ ) during CVVH and CVVHD (Philpott et al., 2019). Dosing of 1-2 g q8-6h are recommended during CRRT under different modalities.

\section{Ceftolozane/Tazobactam}

Ceftolozane/tazobactam is mainly excreted from urine. An ex vivo study showed that ceftolozane/tazobactam transmembrane clearances did not differ at the equivalent effluent rate in $\mathrm{CVVH}$ and CVVHD models, and neither polysulfone nor AN69 membranes absorb ceftolozane/tazobactam. Ceftolozane/ tazobactam clearances mainly depended on effluent flow rates (Chaijamorn et al., 2017). Compared with a patient with normal renal function, a patient who receiving CVVHDF had decreased ceftolozane clearance (Bremmer et al., 2016). During CVVHDF, $0.75 \mathrm{~g}$ q $8 \mathrm{~h}$ in the initial $24 \mathrm{~h}$ could achieve a $40 \% \mathrm{fT}>\mathrm{MIC}$, while doses of at least $1.5 \mathrm{~g} \mathrm{q} 8 \mathrm{~h}$ were required for $100 \% \mathrm{fT}>\mathrm{MIC}$ (Sime et al., 2019). A case study showed the concentrations of ceftolozane were eight times the susceptibility breakpoint for the entire dosing interval after extended-infusion ceftolozane/ tazobactam at $1.5 \mathrm{~g}$ q8h during CVVH (Oliver et al., 2015). Case reports showed that ceftolozane/tazobactam $3 \mathrm{~g}$ q8h continuous infusion could be effective and safe during CVVHDF (Kuti et al., 2016; Aguilar et al., 2019; Mahmoud et al., 2020). Dose regimens range from 1.5 to $4.5 \mathrm{~g}$ daily are recommended according to different effluent flow rates and CRRT modalities.

\section{Sulbactam}

Some $84 \%$ sulbactam were eliminated by the kidney. According to the study on Ampicillin-sulbactam, earlier study indicated sulbactam $1 \mathrm{~g}$ q12h under CVVH and $1 \mathrm{~g}$ q8h under CVVHD or CVVHDF (Trotman et al., 2005). A recent study indicated that the pharmacokinetics of sulbactam in critically ill patients were altered in critically ill patients undergoing CVVH, and a higher dose was recommended (Gao et al., 2016). All patients who receiving a sulbactam dose of $1 \mathrm{~g}$ q8h achieved sulbactam concentrations $>8 \mathrm{mg} / \mathrm{L}$ more than $50 \%$ of the dosing interval for the initial dose, while only three out of eight achieved the trough concentrations $>8 \mathrm{mg} / \mathrm{L}$ at steady stage. Higher dose regimen might be required during $\mathrm{CVVH}$ for less susceptible pathogens. Until now the PK/PD of sulbactam under CVVHDF and CVVHD have not been updated. Therefore, therapeutic drug monitoring (TDM) would be recommended to individualize the dose regimen.

\section{Meropenem}

Meropenem is eliminated by the kidney. CRRT including CVVH (Isla et al., 2008; Bilgrami et al., 2010; Seyler et al., 2011; Beumier et al., 2014; Sime et al., 2018a; Onichimowski et al., 2020b), CVVHDF (Isla et al., 2008; Seyler et al., 2011; Beumier et al., 2014; Varghese et al., 2015), and CVVHD (Afshartous et al., 2014; Kawano et al., 2015; Shaw and Mueller, 2017; NowakKozka et al., 2020; Onichimowski et al., 2020b) could eliminate meropenem. A wide range of meropenem dose regimens from $0.25 \mathrm{~g}$ q24h to $2 \mathrm{~g}$ q $8 \mathrm{~h}$ have been shown to be effective and were recommended for CRRT with diverse effluent flow rates (Kawano et al., 2015; Grensemann et al., 2020). The variable dose regimens are closely related to the MICs of pathogens in order to achieve the different PK/PD goals (e.g., 40\% T > MIC, $100 \% \mathrm{~T}>\mathrm{MIC})$. Additionally, increased total clearance of meropenem was observed in patients with higher creatinine clearance (Isla et al., 2005), residual renal function should also be taken into consideration when adjusting the meropenem dose during CRRT (Ulldemolins et al., 2015). Continuous infusion of meropenem seems to be an effective method to improve the clinical efficacy for patients with less susceptible pathogen infections or augmented renal clearance during CRRT (Langgartner et al., 2008; Burger et al., 2018; Nowak-Kozka et al., 2020). Dose regimens should be adjusted according to different effluent flow rates and MICs of pathogens.

\section{Imipenem}

Imipenem and its metabolites were eliminated in urine. Early study indicated that $1.0 \mathrm{~g} /$ day imipenem achieved concentrations adequate to treat most common gram-negative pathogens (MIC 
up to $2 \mathrm{mg} / \mathrm{L}$ ) and $2.0 \mathrm{~g} /$ day or more may be required to treat the pathogens with $\mathrm{MIC}=4$ to $8 \mathrm{mg} / \mathrm{L}$ during $\mathrm{CVVH}$ or CVVHDF (Fish et al., 2005). A recent study found that high-dose CVVH resulted in a high overall clearance of imipenem (Boucher et al., 2016). Monte Carlo simulations demonstrated that the MIC of pathogens and CRRT intensity (the sum of ultrafiltration rate and dialysis rate) were important factors for dosing strategies of imipenem (Li and Xie, 2019). In summary, the dose regimens of imipenem should be adjusted according to the MIC of pathogens and effluent flow rates.

\section{Panipenem}

Panipenem is primarily excreted by the kidney. A pilot study indicated that total clearance should be calculated to evaluate the dose of panipenem under CRRT. The dose of panipenem should be calculated according to creatinine clearance, dialysate flows and ultrafiltrate flows during CRRT (Hayakawa et al., 2006).

\section{Biapenem}

Biapenem is eliminated by the kidney. The PK/PD of biapenem was only investigated during CVVHDF. About $300 \mathrm{mg}$ q $8 \mathrm{~h}$ had a higher therapeutic efficacy than q12h (Suyama et al., 2008). Early study showed that the minimum dosages to achieve T $>$ MIC of more than $30 \%$ at filtrate-dialysate flow rates of $1.4,2.8$, and 5.6 $\mathrm{L} / \mathrm{h}$ were $300 \mathrm{mg} \mathrm{q} 12 \mathrm{~h}, 600 \mathrm{mg} \mathrm{q} 12 \mathrm{~h}$, and $600 \mathrm{mg} \mathrm{q} 12 \mathrm{~h}$, respectively (Ikawa et al., 2008). Biapenem $300 \mathrm{mg}$ q6h might be an appropriate dose under continuous hemodiafiltration (ultrafiltration rate: $1,000 \mathrm{ml} / \mathrm{h}$, dialysate rate: $500 \mathrm{ml} / \mathrm{h}$ ) (Akashita et al., 2015). Both MICs of pathogens and CRRT effluent flow rates should be considered during biapenem dosing adjustment.

\section{Ertapenem}

Ertapenem is mainly eliminated by kidney. In vitro models demonstrated that ertapenem was cleared substantially under hemodialysis or hemofiltration despite of the high protein binding (Stevenson et al., 2008; Eyler et al., 2014). Ertapenem SA declined with increasing dialysate rates for AN69 hemodiafilters, while SA for polysulfone filters or SC for AN69 and polysulfone filters did not differ at any effluent rates (Stevenson et al., 2008). This effect is due to dialysate traversing more rapidly through the hemodiafilters, however the total clearance was still rising as the dialysate flow increases. Ertapenem dosing regimens (500-1,000 mg daily) could achieve $\geq 40 \% \mathrm{~T}>$ MIC for at least $96 \%$ of patients during CVVHD and CVVHDF (Eyler et al., 2014). Therefore, a range of ertapenem dose regimens from $0.5 \mathrm{~g}$ q24h to $1 \mathrm{~g} \mathrm{q} 24 \mathrm{~h}$ are recommended for CRRT with diverse effluent flow rates.

\section{Doripenem}

Doripenem is eliminated by the kidney. Doripenem was not absorbed onto AN69ST, polymethylmethacrylate, and polysulfone membranes (Hiraiwa et al., 2020). CVVHD could accelerate the elimination of doripenem (Tanoue et al., 2011). The initial dosing recommendation of doripenem for renally competent patients was $500 \mathrm{mg} \mathrm{q} 8 \mathrm{~h}$. Based on this regimen, several studies suggested that doripenem dose should increase to
1.0-1.5 g/day under high flow CVVHDF (Ohchi et al., 2011; Roberts et al., 2014; Tamme et al., 2015). Doripenem clearance was highly correlated with the effluent flow rate during CVVHDF, $250 \mathrm{mg}$ of doripenem $\mathrm{q} 12 \mathrm{~h}$ provided adequate plasma concentrations at a low effluent flow rate (dialysis rate, $500 \mathrm{ml} / \mathrm{h}$; hemofiltration rate, $300 \mathrm{ml} / \mathrm{h}$ ) (Hidaka et al., 2010). In June 2012, the European Medicines Agency concluded that an increased dosage of $1 \mathrm{~g}$ q8h should be employed for renally competent patients. According to the updated dose regimen, studies found that administration of doripenem $1 \mathrm{~g}$ q8h during CRRT was effective and safety (Vossen et al., 2015), and doripenem $1 \mathrm{~g}$ q8h combined with a loading dose of 1.5 to $2 \mathrm{~g}$ may be appropriate for critically ill patients who receiving CVVH, CVVHD, and CVVHDF.

\section{Amikacin}

Amikacin is excreted from urine. A first dose of $\geq 25 \mathrm{mg} / \mathrm{kg}$ amikacin is required to reach therapeutic peak concentrations under CVVHDF (dialysate flow rate: $20-40 \mathrm{ml} / \mathrm{kg} / \mathrm{h}$ and ultrafiltration rate $25-50 \mathrm{ml} / \mathrm{kg} / \mathrm{h}$ ) (Taccone et al., 2011). A strategy of an extended-interval high loading dose of amikacin (25 $\mathrm{mg} / \mathrm{kg}$ every $48 \mathrm{~h}$ ) associated with therapeutic drug monitoring should be the preferred approach for amikacin under CVVH and CVVHDF (30 ml/kg/h) (Roger et al., 2016b). Studies (Lam and Bauer, 2013) observed a wide range of $\mathrm{C}_{\max }$ and $\mathrm{T}_{1 / 2}$ during $\mathrm{CVVHD}$, and indicated that the exact amikacin dosing regimen cannot be accurately predicted based on the dialytic dose or other factors available at the bedside during CVVHD. Amikacin dose regimens should be individualized for each patient on CVVHD based on first-dose PK assessment. No accurate dose regimen has been recommended during CVVHD. Therefore, TDM is recommended to individualize the dose regimen during CRRT.

\section{Ciprofloxacin}

About $50-70 \%$ ciprofloxacin excretes from urine, while $14 \%$ excretes in bile and feces after intravenous administration. CVVHD could eliminate ciprofloxacin (Roehr et al., 2015). The earlier study demonstrated that ciprofloxacin $200 \mathrm{mg}$ q8h might be appropriate under CVVHD with dialysate effluent $3 \mathrm{~L} /$ h (Wallis et al., 2001). Spooner found that $400 \mathrm{mg}$ q12h may be necessary to achieve the desired PK/PD goals in patients for a MIC $\leq 0.5 \mathrm{mg} / \mathrm{L}$ on CVVHDF (dialysate rate: $2 \mathrm{~L} / \mathrm{h}$, ultrafiltration rate: $2 \mathrm{~L} / \mathrm{h}$ ) (Spooner et al., 2011). Roger et al. indicated that a high PK variability of ciprofloxacin was occurred during CVVH and CVVHDF with no significant differences in clearance. High ciprofloxacin dosing (400 mg q8h) should be used during CVVH (ultrafiltration rate: $30 \mathrm{ml} / \mathrm{kg} / \mathrm{h}$ ) or CVVHDF (ultrafiltration rate: $15 \mathrm{ml} / \mathrm{kg} / \mathrm{h}$, dialysate rate: $15 \mathrm{ml} / \mathrm{kg} / \mathrm{h}$ ) if TDM is not routinely available (Roger et al., 2016a). In summary, $200 \mathrm{mg}$ to $400 \mathrm{mg} \mathrm{q} 8 \mathrm{~h}$ are recommended under diverse effluent flow rates and CRRT modalities.

\section{Levofloxacin}

Levofloxacin is excreted largely as unchanged drug in the urine. Early study indicated that $250 \mathrm{mg}$ q $24 \mathrm{~h}$ was suitable under CVVH (ultrafiltration rate: $14-23 \mathrm{ml} / \mathrm{min}$ ), CVVHDF 
(dialysate rate: $0.8-1.5 \mathrm{ml} / \mathrm{min}$, ultrafiltration rate $9-23 \mathrm{ml} / \mathrm{min}$ ) (Malone et al., 2001). Monte Carlo simulations found that none of the recommended dosing regimens of levofloxacin (from 314 $\mathrm{mg} \mathrm{q} 48 \mathrm{~h}$ to $750 \mathrm{mg} \mathrm{LD}, 500 \mathrm{mg}$ q24 h) attained the probability of target attainment goal (daily average AUC/MIC $\geq 125$ for the first $72 \mathrm{~h}$ of treatment) during CVVHD (dialysate rate: 25 or $30 \mathrm{ml} /$ $\mathrm{kg} / \mathrm{L}$ ), and therefore levofloxacin should not be used as monotherapy to treat gram-negative infections in CVVHD patients (Shaw and Mueller, 2017). According to the limited study, levofloxacin $250 \mathrm{mg}$ daily might be appropriate during CVVH and CVVHDF with a relative low CRRT intensity.

\section{Colistin}

Colistin methanesulfonate (CMS), is the prodrug of colistin. CRRT has a dramatic impact on the pharmacokinetics of CMS, and the dose requirements of CMS are greater in patients on CRRT than for patients with normal renal function (Tsuji et al., 2019). Patients undergoing CVVH can be treated with long-term colistin therapy at doses of 3-4.5 million IU tid with a high loading dose (e.g., 9 million IU) (Honore et al., 2014; Menna et al., 2018; Spapen et al., 2019). Both CMS and colistin can be efficiently cleared by CVVHD (Leuppi-Taegtmeyer et al., 2019) and CVVHDF (Li et al., 2005; Karvanen et al., 2013; Karaiskos et al., 2016), and using a loading dose helped to achieve target colistin concentration more rapidly. A loading colistin base activity $(\mathrm{CBA})$ dosage of $\mathrm{C}_{\mathrm{ss} \text {,avg }}(\mathrm{mg} / \mathrm{L}) \times 2.0 \times$ body weight $(\mathrm{kg})$, and maintain dosage of $192 \mathrm{mg} \times \mathrm{C}_{\mathrm{ss} \text {,avg }}(\mathrm{mg} / \mathrm{L}) \mathrm{q} 8-12 \mathrm{~h}$ were suitable for individual patient under CVVHD (Garonzik et al., 2011). A loading dose of 12 million IU and a maintenance dose of at least 6.5-7.5 million IU were suitable for patients undergoing CVVHDF according to a predicted pharmacokinetic model, but the safety of this high loading dose needs to be assessed (Karaiskos et al., 2016). CMS or CBA dose regimens during CRRT should be managed by a high loading dose followed by maintenance dosages based on diverse CRRT modalities and intensity.

\section{Vancomycin}

About $80-90 \%$ vancomycin is excreted as unchanged drug in the first $24 \mathrm{~h}$ from urine. Vancomycin serum levels are difficult to maintain in CRRT patients (Omrani et al., 2015), and are significantly affected by CRRT intensity (Beumier et al., 2013). Early study suggested vancomycin $1 \mathrm{~g}$ q48h under CVVH and $1 \mathrm{~g}$ q24h under CVVHD and CVVHDF (Trotman et al., 2005). This is inconsistent with theoretical knowledge: since vancomycin is a relatively large molecule drug, therefore it would be cleared more efficiently by CVVH than CVVHD theoretically. The Japanese Society of Chemotherapy and the Japanese Society of Therapeutic Drug Monitoring recommended that an initial dose of $15-20 \mathrm{mg} / \mathrm{kg}$, and doses of $500 \mathrm{mg}(7.5-10 \mathrm{mg} / \mathrm{kg})$ are given $\mathrm{q} 24 \mathrm{~h}$ as maintenance doses for patients under CVVHDF (Matsumoto et al., 2013). A 1.5 g loading dose followed by continuous infusion of 1-1.5 g IV over $24 \mathrm{~h}$ would be recommended for patients undergoing CVVHD (van de Vijsel et al., 2010). Previous studies showed quite different recommendations on vancomycin dosage under CVVH. Chaijamorn $\mathrm{W}$ indicated the maintenance dose of vancomycin would be 500-750 mg q12h to provide a trough concentration of 15-20 mg/L under CVVH with an ultrafiltrate flow rate of 800$1,200 \mathrm{ml} / \mathrm{h}$ (Chaijamorn et al., 2011), while Qiang Li recommended vancomycin 400-650 $\mathrm{mg}$ q12h under CVVH with an ultrafiltrate flow rate of $30-40 \mathrm{mg} / \mathrm{kg} / \mathrm{h}$ (Li et al., 2020). The latest study showed a higher dose (total dose $\geq 2.75 \mathrm{~g} /$ day) of vancomycin than the current recommendation (highest literature-based dosing regimen: $1.5 \mathrm{~g} /$ day) was needed in CRRT patients with vancomycin $\mathrm{MIC} \geq 1 \mathrm{mg} / \mathrm{L}$ (Charoensareerat et al., 2019). Due to inconsistent dosing recommendations in the literatures, it is recommended to adjust the individual dose according to TDM.

\section{Teicoplanin}

Teicoplanin is mainly eliminated by the kidney. A loading dose of $1,200 \mathrm{mg}$, and maintenance doses of $600-1,800 \mathrm{mg}$ q24h to achieve trough levels of $15-25 \mathrm{mg} / \mathrm{L}$ under CVVH was recommended (Bellmann et al., 2010). Considering the large molecular weight of teicoplanin, CVVHD may not eliminate teicoplanin efficiently. Early study indicated a loading dose of $800 \mathrm{mg}$ and maintenance dose of $400 \mathrm{mg} \mathrm{q48-72h}$ under CVVHD (Wolter et al., 1994). CVVHDF could partly eliminate the teicoplanin according to the pharmacokinetics study, no exact dose was recommended during CVVHDF (Yagasaki et al., 2003). Due to the lacking of updated information on teicoplanin during CRRT, we suggest that TDM for the teicoplanin should be performed.

\section{Daptomycin}

About 78\% daptomycin is excreted in urine as unchanged drug. Some studies indicated that during CVVHDF or CVVHD (combined dialysate and ultrafiltration rate: $30-40 \mathrm{ml} / \mathrm{kg} / \mathrm{h}$ ), no significant accumulation occurred with a usual dose of daptomycin in patients with normal kidney function $(6 \mathrm{mg} / \mathrm{kg}$ q24h) (Corti et al., 2013), and daptomycin exposure with oncedaily dosing (ranged from 3 to $8 \mathrm{mg} / \mathrm{kg}$ q24h) was similar to ICU patients with normal renal function, but lower compared to healthy volunteers (Preiswerk et al., 2013). Daptomycin at $8 \mathrm{mg} /$ $\mathrm{kg}$ q48h in patients receiving CVVHD achieved higher peak and lower trough concentrations compared with $4 \mathrm{mg} / \mathrm{kg}$ q24h, which maximize daptomycin's concentration-dependent activity and minimize the risk of myopathy (Vilay et al., 2011). A higher dosage regimen ( $8 \mathrm{mg} / \mathrm{kg} \mathrm{q} 24 \mathrm{~h})$ was shown to be appropriate for patients during CVVHDF (Xu et al., 2017). However, a recent study found that $8 \mathrm{mg} / \mathrm{kg}$ q24h daptomycin has a high probability of reaching the toxicity-related concentration threshold, while $6 \mathrm{mg} / \mathrm{kg}$ q24h gave a satisfactory risk-benefit balance during CVVHDF or CVVHD (Xie et al., 2020). In summary, daptomycin 6-8 mg/kg q24h might be appropriate during CVVHDF or CVVHD, and adverse effects should be carefully monitored after application of high dose daptomycin.

\section{Sulfamethoxazole (SMX)/Trimethoprim (TMP)}

SMX/TMP are mainly excreted from urine. Case study indicated that both TMP and SMX are removed by CVVHDF (dialysate rate: $1.5 \mathrm{~L} / \mathrm{h}$, ultrafiltration rate: 1.5 or $2.55 \mathrm{~L} / \mathrm{h}$ ) to a significant 
degree (Curkovic et al., 2010). SMX clearance in CVVHDF showed high variability, and no accurate doses were recommended during CVVHDF. Transmembrane clearance of TMP is greater than SMX. In vitro study found that TMP $10 \mathrm{mg} /$ $\mathrm{kg} /$ day and the corresponded SMX dose $(50 \mathrm{mg} / \mathrm{kg} /$ day $)$ resulted in steady state TMP peak concentrations between 5 and $10 \mathrm{mg} / \mathrm{L}$ and steady state SMX peak concentrations between 100 and 200 $\mathrm{mg} / \mathrm{L}$, which were associated with efficacy against $P$. jirovecii. TMP $10 \mathrm{mg} / \mathrm{kg} /$ day divided q12h may be an appropriate initial dose to consider in patients undergoing CVVH or CVVHD (ultrafiltration/dialysate rates: 1, 2, 3, and $6 \mathrm{~L} / \mathrm{h}$ ) (Kesner et al., 2014).

\section{Fluconazole}

Some $80 \%$ of fluconazole is eliminated by urine as unchanged drug. Early studies indicated that a dose of $800 \mathrm{mg}$ q24h was suitable for patients receiving CVVHD or CVVHDF, while a dose of $400 \mathrm{mg}$ q24h was suitable for patients receiving $\mathrm{CVVH}$ (Trotman et al., 2005). The recommended dose regimens were higher during hemodialysis than hemofiltration. The recommended dose regimens have increased due to the increase of ultrafiltrate or dialysate rates. A recent study found that a higher dose regimen (loading dose: $900 \mathrm{mg}$, maintenance dose: $600 \mathrm{mg} \mathrm{q12h}$ ) could reach the theoretical target of 16-32 $\mathrm{mg} / \mathrm{L}$ peak and $10 \mathrm{mg} / \mathrm{L}$ trough concentrations during CVVHD at a high flow rate (Oualha et al., 2019). Monte Carlo simulations found that a dose of $400 \mathrm{mg}$ q12h maximizes empirical treatment against fungal organisms with $\mathrm{MIC}$ up to $16 \mathrm{mg} / \mathrm{L}$ under CVVHDF (Patel et al., 2011). A case report of an obese patient showed that a fluconazole dose of $6 \mathrm{mg} / \mathrm{kg}$ lean body weight daily was able to achieve pharmacodynamic goals (AUC: MIC $\geq 25$ ) during CVVH (Lopez and Phillips, 2014). The phenomenon could be explained by the low molecular weight and low protein binding of fluconazole, which make it easy to pass through the dialysis membrane through diffusion. MICs of pathogens, CRRT modalities and effluent flow rates should be considered during fluconazole dosing adjustment.

\section{Acyclovir}

Acyclovir is mainly secreted and excreted by renal glomerular filtration and renal tubules. It could be cleared by renal replacement therapy. Acyclovir 5-7.5 mg/kg q24h was recommended under CVVH, CVVHD and CVVHDF previously (Trotman et al., 2005). Adding acyclovir (5.5 mg/L) to the dialysate fluid during CRRT was reported to be effective in achieving therapeutic drug concentrations (Cies et al., 2015). There are no effective new studies providing the specific dose of acyclovir in different CRRT modes. Individual TDM for acyclovir is required to optimize therapy for patients undergoing CRRT (Funaki et al., 2015).

\section{Ganciclovir}

Ganciclovir is mainly excreted through kidney. Early study found that ganciclovir $5 \mathrm{mg} / \mathrm{kg}$ q $48 \mathrm{~h}$ was suitable during CVVHD with a dialysate flow rate $1 \mathrm{~L} / \mathrm{h}$ (Bastien et al., 1994). Horvatits et al. found that ganciclovir $2.5 \mathrm{mg} / \mathrm{kg}$ q24h was appropriate undern CVVHDF (ultrafiltration rate: $1 \mathrm{~L} / \mathrm{h}$ plus dialysate flow rate: $1 \mathrm{~L} / \mathrm{h}$ ) (Horvatits et al., 2014). However, another case report found that the concentration of ganciclovir $(2.5 \mathrm{mg} / \mathrm{kg}$ q24h) was not significantly affected by CVVHDF (ultrafiltration rate: $0.2 \mathrm{~L} /$ $\mathrm{h}$ plus dialysate flow rate: $1 \mathrm{~L} / \mathrm{h}$ ), and the dose would be recommended as the same as the dose for patients with creatinine clearance $<25 \mathrm{ml} / \mathrm{min}$ (McGloughlin et al., 2011). We speculated that the difference between the two studies may partly due the different ultrafiltration rate. Evidences are inadequate in further studies for ganciclovir during CRRT.

\section{Oseltamivir}

More than 99\% of oseltamivir active metabolism is excreted by the kidney. A case report showed the accumulation of oseltamivir during CVVHDF (Lemaitre et al., 2010). Studies found that oseltamivir $150 \mathrm{mg}$ q12h under CVVHD (Eyler et al., 2012) and $75 \mathrm{mg}$ or $150 \mathrm{mg}$ q12h under CVVHDF (Lemaitre et al., 2012) yielded a median oseltamivir carboxylate $\mathrm{AUC}_{0-12}$ considerably higher than non-critically ill patients. These studies indicated that the doses of oseltamivir should reduce during CRRT. However, no accurate data was recommended. On the other hand, the investigated dose of oseltamivir (150 mg q12h) which was recommended by WHO for severe illness (Eyler et al., 2012) is higher than the usual oseltamivir dose $75 \mathrm{mg} \mathrm{q} 12 \mathrm{~h}$, therefore the recommended dose might need to be less than $75 \mathrm{mg} \mathrm{q12h}$ for non-critically ill patients.

\section{Peramivir}

Peramivir is excreted mainly through urine. Peramivir could be cleared by CRRT including CVVH (Scheetz et al., 2011) and CVVHDF (Bentley et al., 2014). Under CVVH, the SC of peramivir was 0.9 , and drug exposure is potentially predictable based on flow rates (Scheetz et al., 2011). Meanwhile, the SA of peramivir was 1 during CVVHDF (Bentley et al., 2014). The high SC and SA of peramivir during CRRT indicated that is readily cleared by CRRT. The number of patients was small in the studies on peramivir during CRRT. According to the limited data, peramivir $600 \mathrm{mg}$ q24h was suitable during CVVH or CVVHDF (Bazan et al., 2010; Scheetz et al., 2011).

\section{Antimicrobials Which Do Not Need Dosing Adjustment}

Classically, drugs with high protein binding and predominantly non-renal elimination are not removed by CRRT. Quite a few studies investigated the PKs of drugs with these properties. Ceftriaxone elimination via renal and biliary routes is about equal, while ceftriaxone clearance in patients receiving $\mathrm{CVVH}$ was equivalent to clearance in subjects with normal renal function (Trotman et al., 2005). The estimated Ceftriaxone clearance by CVVH was about $70 \%$ of total body clearance, and Ceftriaxone could be used safely against pathogens with a MIC $\leq 2 \mu \mathrm{g} / \mathrm{ml}$ (Goto et al., 2016). The PK parameters of moxifloxacin during hemodialysis were similar to patients without renal impairment (Fuhrmann et al., 2004; Tokimatsu et al., 2017). A population pharmacokinetic study showed that no dose adjustment of tigecycline seems necessary in CRRT (Broeker et al., 2018). Dosage modifications are warranted in patients receiving polymyxin $\mathrm{B}$ which is eliminated via a 
nonrenal route under CRRT (Tsuji et al., 2019). A PK case study indicated that no supranormal posaconazole accumulation is anticipated in a patient during CVVHDF (flow rate:1 L/h) (Sime et al., 2018b). No significant influence of CVVH on the pharmacokinetics of amphotericin B (AMB) lipid complexes has been found (Bellmann et al., 2003). CVVHDF had no clinically significant effect on the pharmacokinetics of AMB following administration of AMB lipid complexes (Malone et al., 2013). A standard dose of these antimicrobials can be recommended for patients during CRRT. Although little is known about the PK parameters of clindamycin and azithromycin during different CRRT modalities, considering their non-renal elimination, studies suggested that no dose adjustment is required during CRRT (Pistolesi et al., 2019).

A systematic review found a wide variability in linezolid PK/ PD parameters across critically ill septic patients with AKI treated with CRRT (Villa et al., 2016). In patients with residual renal function, $900 \mathrm{mg} \mathrm{q} 8 \mathrm{~h}$ provide a high probability of treatment success without compromising the safety during CVVHD or CVVHDF (flow rate: 1,031 $\pm 634 \mathrm{ml} / \mathrm{h}$ ) (Barrasa et al., 2019). Strategies such as TDM should be applied to improve the effectiveness of linezolid therapy under CRRT (Ide et al., 2018).

Oral formulation of voriconazole does not require dose adjustment under CRRT due to the non-renal elimination of voriconazole. The parenteral formulation is solubilized in sulfobutylether- $\beta$-cyclodextrin (SBECD), which would accumulate in patients with impaired renal function. A recent study found that SBECD could be removed by CVVH effectively (Kiser et al., 2015). Standard doses of intravenous voriconazole can be used in patients undergoing $\mathrm{CVVH}$ without significant risk of SBECD accumulation.

Caspofungin exposure during CVVH or CVVHD was very similar to that in healthy volunteers (Weiler et al., 2013). No caspofungin dosing adjustment is necessary for patients undergoing either form of CRRT (Roger et al., 2017b). Recent studies report different proportions of echinocandins lost by filter adsorption (Vossen et al., 2017). Unlike caspofungin, micafungin is not administered in a loading dose. Thus, the concentration of micafungin on the first day might be compromised by drug loss due to adsorption in a hemofilter, especially when highabsorptive capacity membranes and medium- to high-volume convection flows are used. The proportion of drug lost in micafungin may be clinically relevant (Gonzalez et al., 2014). Further studies should be conducted focusing on echinocandins dosing on CRRT with highly absorptive membrane filters.

\section{REFERENCES}

Afshartous, D., Bauer, S. R., Connor, M. J., Aduroja, O. A., Amde, M., Salem, C., et al. (2014). Pharmacokinetics and pharmacodynamics of imipenem and meropenem in critically ill patients treated with continuous venovenous hemodialysis. Am. J. Kidney Dis. 63, 170-171. doi: 10.1053/j.ajkd.2013.08.015 Aguilar, G., Ferriols, R., Martinez-Castro, S., Ezquer, C., Pastor, E., Carbonell, J. A., et al. (2019). Optimizing ceftolozane-tazobactam dosage in critically ill patients during continuous venovenous hemodiafiltration. Crit. Care 23, 145. doi: 10.1186/s13054-019-2434-5

\section{FURTHER DIRECTIONS AND CONCLUSION}

The wide variation in CRRT techniques and the heterogeneity of the critically ill patients made it difficult to decide the appropriate dosing during CRRT. Here CRRT modalities and the effluent flow rates are regarded as the main differences in the therapies. Our review provides empirical dosing strategies for the antimicrobials during CRRT based on the various CRRT modes. However, some of the recommendations were based on Monte Carlo methods and some were acquired from studies with limited samples. The majority of these recommendations are regardless of residual renal function. For patients who have residual renal function, the clearance of antimicrobials which are eliminated by kidney would elevate, corresponding increases in doses may be required. Considering the patient variability in $\mathrm{PK} / \mathrm{PD}$ parameters and the different CRRT settings, therapeutic drug monitoring is suggested to optimize therapy after empirical therapy.

\section{AUTHOR CONTRIBUTIONS}

LL summarized the CRRT factors, wrote and edit the manuscript. XLi summarized the dosing of quinolones and aminoglycoside. YX summarized the dosing of carbapenases. YC summarized the dosing of cephalosporin and penicillins. HZ summarized the dosing of triazoles. JL summarized the dosing of colistin and glycopeptides. PL summarized the dosing of antiviral agents. YB summarized the dosing of echinocandins and amphotericin B. RZ summarized the dosing of tetracyclines and macrolides. YL summarized the dosing of linezolid and daptomycin. PY summarized the drug properties during CRRT. XLu designed the revised content, reviewed and edited the manuscript. SJ designed the content, reviewed and edited the manuscript.

\section{FUNDING}

This work was supported by The National Natural Science Foundation of China (No. 81671889, No. 81703578, and No. 81800594), and the Fundamental Research Funds for the Central Universities (2019QNA7032). 
Barrasa, H., Soraluce, A., Isla, A., Martin, A., Maynar, J., Canut, A., et al. (2019). Pharmacokinetics of linezolid in critically ill patients on continuous renal replacement therapy: influence of residual renal function on $\mathrm{pk} / \mathrm{pd}$ target attainment. J. Crit. Care 50, 69-76. doi: 10.1016/j.jcrc.2018.11.016

Bastien, O., Boulieu, R., Bleyzac, N., and Estanove, S. (1994). Clinical use of ganciclovir during renal failure and continuous hemodialysis. Intensive Care Med. 20, 47-48. doi: 10.1007/bf02425056

Bazan, J. A., Bauer, K. A., Hollister, A. S., Shidham, G., Firstenberg, M. S., Reed, E. E., et al. (2010). Peramivir pharmacokinetics in two critically ill adults with $2009 \mathrm{~h} 1 \mathrm{n} 1$ influenza a concurrently receiving continuous renal replacement therapy. Pharmacotherapy 30, 1016-1020. doi: 10.1592/phco.30.10.1016

Bellmann, R., Egger, P., Gritsch, W., Bellmann-Weiler, R., Joannidis, M., Kaneider, N., et al. (2003). Amphotericin b lipid formulations in critically ill patients on continuous veno-venous haemofiltration. J. Antimicrob Chemother. 51, 671681. doi: 10.1093/jac/dkg139

Bellmann, R., Falkensammer, G., Seger, C., Weiler, S., Kountchev, J., Joannidis, M., et al. (2010). Teicoplanin pharmacokinetics in critically ill patients on continuous veno-venous hemofiltration. Int. J. Clin. Pharmacol. Ther. 48, 243-249.

Bellomo, R., Kellum, J. A., Ronco, C., Wald, R., Martensson, J., Maiden, M., et al. (2017). Acute kidney injury in sepsis. Intensive Care Med. 43, 816-828. doi: 10.1007/s00134-017-4755-7

Bentley, M. L., Hollistera, A. S., Hansenb, A. C., Smith, J. A., and Cain, J. S. (2014). Peramivir pharmacokinetics in a patient receiving continuous veno-venous hemodiafiltration during the 2009 hln1 influenza a pandemic. Int. J. Clin. Pharmacol. Ther. 52, 1105-1111. doi: 10.5414/CP202161

Beumier, M., Roberts, J. A., Kabtouri, H., Hites, M., Cotton, F., Wolff, F., et al. (2013). A new regimen for continuous infusion of vancomycin during continuous renal replacement therapy. J. Antimicrob Chemother. 68, 28592865. doi: 10.1093/jac/dkt261

Beumier, M., Casu, G. S., Hites, M., Seyler, L., Cotton, F., Vincent, J. L., et al. (2014). Beta-lactam antibiotic concentrations during continuous renal replacement therapy. Crit. Care 18, R105. doi: 10.1186/cc13886

Bilgrami, I., Roberts, J. A., Wallis, S. C., Thomas, J., Davis, J., Fowler, S., et al. (2010). Meropenem dosing in critically ill patients with sepsis receiving highvolume continuous venovenous hemofiltration. Antimicrob Agents Chemother. 54, 2974-2978. doi: 10.1128/AAC.01582-09

Bouchard, J., Weidemann, C., and Mehta, R. L. (2008). Renal replacement therapy in acute kidney injury: intermittent versus continuous? How much is enough? Adv. Chronic Kidney Dis. 15, 235-247. doi: 10.1053/ j.ackd.2008.04.004

Boucher, B. A., Hudson, J. Q., Hill, D. M., Swanson, J. M., Wood, G. C., Laizure, S. C., et al. (2016). Pharmacokinetics of imipenem/cilastatin burn intensive care unit patients undergoing high-dose continuous venovenous hemofiltration. Pharmacotherapy 36, 1229-1237. doi: 10.1002/phar.1866

Bouman, C. S., van Kan, H. J., Koopmans, R. P., Korevaar, J. C., Schultz, M. J., Vroom, M. B., et al. (2006). Discrepancies between observed and predicted continuous venovenous hemofiltration removal of antimicrobial agents in critically ill patients and the effects on dosing. Intensive Care Med. 32, 20132019. doi: 10.1007/s00134-006-0397-x

Bremmer, D. N., Nicolau, D. P., Burcham, P., Chunduri, A., Shidham, G., Bauer, K. A., et al. (2016). Ceftolozane/tazobactam pharmacokinetics in a critically ill adult receiving continuous renal replacement therapy. Pharmacotherapy 36, e30-e33. doi: 10.1002/phar.1744

Broeker, A., Wicha, S. G., Dorn, C., Kratzer, A., Schleibinger, M., Kees, F., et al. (2018). Tigecycline in critically ill patients on continuous renal replacement therapy: a population pharmacokinetic study. Crit. Care 22, 341. doi: 10.1186/ s13054-018-2278-4

Brown, G. R. (2014). Cotrimoxazole - optimal dosing in the critically ill. Ann. Intensive Care 4, 13. doi: 10.1186/2110-5820-4-13

Burger, R., Guidi, M., Calpini, V., Lamoth, F., Decosterd, L., Robatel, C., et al. (2018). Effect of renal clearance and continuous renal replacement therapy on appropriateness of recommended meropenem dosing regimens in critically ill patients with susceptible life-threatening infections. J. Antimicrob Chemother. 73, 3413-3422. doi: 10.1093/jac/dky370

Carlier, M., Taccone, F. S., Beumier, M., Seyler, L., Cotton, F., Jacobs, F., et al. (2015). Population pharmacokinetics and dosing simulations of cefepime in septic shock patients receiving continuous renal replacement therapy. Int. J. Antimicrob Agents 46, 413-419. doi: 10.1016/j.ijantimicag.2015.05.020
Chaijamorn, W., Jitsurong, A., Wiwattanawongsa, K., Wanakamanee, U., and Dandecha, P. (2011). Vancomycin clearance during continuous venovenous haemofiltration in critically ill patients. Int. J. Antimicrob Agents 38, 152-156. doi: 10.1016/j.ijantimicag.2011.04.010

Chaijamorn, W., Shaw, A. R., Lewis, S. J., and Mueller, B. A. (2017). Ex vivo ceftolozane/tazobactam clearance during continuous renal replacement therapy. Blood Purif 44, 16-23. doi: 10.1159/000455897

Chaijamorn, W., Charoensareerat, T., Srisawat, N., Pattharachayakul, S., and Boonpeng, A. (2018). Cefepime dosing regimens in critically ill patients receiving continuous renal replacement therapy: a monte carlo simulation study. J. Intensive Care 6, 61. doi: 10.1186/s40560-018-0330-8

Charoensareerat, T., Chaijamorn, W., Boonpeng, A., Srisawat, N., Pummangura, C., and Pattharachayakul, S. (2019). Optimal vancomycin dosing regimens for critically ill patients with acute kidney injury during continuous renal replacement therapy: a monte carlo simulation study. J. Crit. Care 54, 77-82. doi: $10.1016 /$ j.jcrc.2019.07.008

Cies, J. J., Moore, W. N., Miller, K., Small, C., Carella, D., Conley, S., et al. (2015). Therapeutic drug monitoring of continuous-infusion acylovir for disseminated herpes simplex virus infection in a neonate receiving concurrent extracorporeal life support and continuous renal replacement therapy. Pharmacotherapy 35, 229-233. doi: 10.1002/phar.1526

Corti, N., Rudiger, A., Chiesa, A., Marti, I., Jetter, A., Rentsch, K., et al. (2013). Pharmacokinetics of daily daptomycin in critically ill patients undergoing continuous renal replacement therapy. Chemotherapy 59, 143-151. doi: 10.1159/000353400

Curkovic, I., Luthi, B., Franzen, D., Ceschi, A., Rudiger, A., and Corti, N. (2010). Trimethoprim/sulfamethoxazole pharmacokinetics in two patients undergoing continuous venovenous hemodiafiltration. Ann. Pharmacother. 44, 1669-1672. doi: 10.1345/aph.1P160

Deepa, C., and Muralidhar, K. (2012). Renal replacement therapy in icu. J. Anaesthesiol Clin. Pharmacol. 28, 386-396. doi: 10.4103/0970-9185.98357

Eyler, R. F., Heung, M., Pleva, M., Sowinski, K. M., Park, P. K., Napolitano, L. M., et al. (2012). Pharmacokinetics of oseltamivir and oseltamivir carboxylate in critically ill patients receiving continuous venovenous hemodialysis and/or extracorporeal membrane oxygenation. Pharmacotherapy 32, 1061-1069. doi: 10.1002/phar.1151

Eyler, R. F., Vilay, A. M., Nader, A. M., Heung, M., Pleva, M., Sowinski, K. M., et al. (2014). Pharmacokinetics of ertapenem in critically ill patients receiving continuous venovenous hemodialysis or hemodiafiltration. Antimicrob Agents Chemother. 58, 1320-1326. doi: 10.1128/AAC.02090-12

Fish, D. N., Teitelbaum, I., and Abraham, E. (2005). Pharmacokinetics and pharmacodynamics of imipenem during continuous renal replacement therapy in critically ill patients. Antimicrob Agents Chemother. 49, 24212428. doi: 10.1128/AAC.49.6.2421-2428.2005

Fuhrmann, V., Schenk, P., Jaeger, W., Ahmed, S., and Thalhammer, F. (2004). Pharmacokinetics of moxifloxacin in patients undergoing continuous venovenous haemodiafiltration. J. Antimicrob Chemother. 54, 780-784. doi: $10.1093 / \mathrm{jac} / \mathrm{dkh} 421$

Funaki, T., Miyata, I., Shoji, K., Enomoto, Y., Sakamoto, S., Kasahara, M., et al. (2015). Therapeutic drug monitoring in neonatal hsv infection on continuous renal replacement therapy. Pediatrics 136, e270-e274. doi: 10.1542/peds.20143380

Gao, C., Tong, J., Yu, K., Sun, Z., An, R., Du, Z., et al. (2016). Pharmacokinetics of cefoperazone/sulbactam in critically ill patients receiving continuous venovenous hemofiltration. Eur. J. Clin. Pharmacol. 72, 823-830. doi: 10.1007/s00228-016-2045-x

Garonzik, S. M., Li, J., Thamlikitkul, V., Paterson, D. L., Shoham, S., Jacob, J., et al. (2011). Population pharmacokinetics of colistin methanesulfonate and formed colistin in critically ill patients from a multicenter study provide dosing suggestions for various categories of patients. Antimicrob Agents Chemother. 55, 3284-3294. doi: 10.1128/AAC.01733-10

Gonzalez, D. M. F., Martinez-Alberici, M. L., and Ferrer, R. (2014). Treatment with echinocandins during continuous renal replacement therapy. Crit. Care 18, 218. doi: 10.1186/cc13803

Goto, K., Sato, Y., Yasuda, N., Hidaka, S., Suzuki, Y., Tanaka, R., et al. (2016). Pharmacokinetics of ceftriaxone in patients undergoing continuous renal replacement therapy. J. Basic Clin. Physiol. Pharmacol. 27, 625-631. doi: $10.1515 /$ jbcpp-2016-0022 
Grensemann, J., Busse, D., Konig, C., Roedl, K., Jager, W., Jarczak, D., et al. (2020). Acute-on-chronic liver failure alters meropenem pharmacokinetics in critically ill patients with continuous hemodialysis: an observational study. Ann. Intensive Care 10, 48. doi: 10.1186/s13613-020-00666-8

Hayakawa, M., Ito, Y., Fujita, I., Iseki, K., and Gando, S. (2006). Pharmacokinetics and the most suitable regimen of panipenem/beta mipron in critically ill patients receiving continuous renal replacement therapy: a pilot study. Asaio J. 52, 398-403. doi: 10.1097/0.1mat.0000225268.28044.ae

Heintz, B. H., Matzke, G. R., and Dager, W. E. (2009). Antimicrobial dosing concepts and recommendations for critically ill adult patients receiving continuous renal replacement therapy or intermittent hemodialysis. Pharmacotherapy 29, 562-577. doi: 10.1592/phco.29.5.562

Hidaka, S., Goto, K., Hagiwara, S., Iwasaka, H., and Noguchi, T. (2010). Doripenem pharmacokinetics in critically ill patients receiving continuous hemodiafiltration (chdf). Yakugaku Zasshi 130, 87-94. doi: 10.1248/ yakushi.130.87

Hiraiwa, T., Moriyama, K., Matsumoto, K., Shimomura, Y., Kato, Y., Yamashita, C., et al. (2020). In vitro evaluation of linezolid and doripenem clearance with different hemofilters. Blood Purif. 49, 295-301. doi: 10.1159/000504039

Hoff, B. M., Maker, J. H., Dager, W. E., and Heintz, B. H. (2019). Antibiotic dosing for critically ill adult patients receiving intermittent hemodialysis, prolonged intermittent renal replacement therapy, and continuous renal replacement therapy: an update. Ann. Pharmacother. 54, 43-55. doi: 10.1177/ 1060028019865873

Honore, P. M., Jacobs, R., Joannes-Boyau, O., Lochy, S., Boer, W., De Waele, E., et al. (2014). Continuous renal replacement therapy-related strategies to avoid colistin toxicity: a clinically orientated review. Blood Purif. 37, 291-295. doi: $10.1159 / 000363495$

Horvatits, T., Kitzberger, R., Drolz, A., Zauner, C., Jäger, W., Böhmdorfer,M., et al. (2014). Pharmacokinetics of ganciclovir during continuous venovenous hemodiafiltration in critically ill patients. Antimicrob Agents Chemother. 58, 94-101. doi: 10.1128/AAC.00892-13

Ide, T., Takesue, Y., Ikawa, K., Morikawa, N., Ueda, T., Takahashi,Y., et al. (2018). Population pharmacokinetics/pharmacodynamics of linezolid in sepsis patients with and without continuous renal replacement therapy. Int. J. Antimicrob Agents 51, 745-751. doi: 10.1016/j.ijantimicag.2018.01.021

Ikawa, K., Morikawa, N., Ikeda, K., and Suyama, H. (2008). Pharmacokinetic modeling and dosage adaptation of biapenem in japanese patients during continuous venovenous hemodiafiltration. J. Infect. Chemother. 14, 35-39. doi: 10.1007/s10156-007-0572-1

Isla, A., Maynar, J., Sanchez-Izquierdo, J. A., Gascon, A. R., Arzuaga, A. , Corral,E., et al. (2005). Meropenem and continuous renal replacement therapy: in vitro permeability of 2 continuous renal replacement therapy membranes and influence of patient renal function on the pharmacokinetics in critically ill patients. J. Clin. Pharmacol. 45, 1294-1304. doi: 10.1177/0091270005280583

Isla, A., Rodriguez-Gascon, A., Troconiz, I. F., Bueno, L., Solinis, M. A., Maynar, J., et al. (2008). Population pharmacokinetics of meropenem in critically ill patients undergoing continuous renal replacement therapy. Clin. Pharmacokinet 47, 173-180. doi: 10.2165/00003088-200847030-00003

Jamal, J. A., Udy, A. A., Lipman, J., and Roberts, J. A. (2014). The impact of variation in renal replacement therapy settings on piperacillin, meropenem, and vancomycin drug clearance in the critically ill: an analysis of published literature and dosing regimens* ${ }^{*}$ Crit. Care Med. 42, 1640-1650. doi: 10.1097/ CCM.0000000000000317

Jamal, J. A., Roberts, D. M., Udy, A. A., Mat-Nor, M. B., Mohamad-Nor, F., Wallis, S. C., et al. (2015). Pharmacokinetics of piperacillin in critically ill patients receiving continuous venovenous haemofiltration: a randomised controlled trial of continuous infusion versus intermittent bolus administration. Int. J. Antimicrob Agents 46, 39-44. doi: 10.1016/j.ijantimicag.2015.02.014

Jang, S. M., Pai, M. P., Shaw, A. R., and Mueller, B. A. (2019). Antibiotic exposure profiles in trials comparing intensity of continuous renal replacement therapy. Crit. Care Med. 47, e863-e871. doi: 10.1097/CCM.0000000000003955

Jiang, S. P., Zhu, Z. Y., Wu, X. L., Lu, X. Y., Zhang, X. G., and Wu, B. (2014). Effectiveness of pharmacist dosing adjustment for critically ill patients receiving continuous renal replacement therapy: a comparative study. Ther. Clin. Risk Manag. 10, 405-412. doi: 10.2147/TCRM.S59187

Karaiskos, I., Friberg, L. E., Galani, L., Ioannidis, K., Katsouda, E., Athanassa, Z., et al. (2016). Challenge for higher colistin dosage in critically ill patients receiving continuous venovenous haemodiafiltration. Int. J. Antimicrob Agents 48, 337-341. doi: 10.1016/j.ijantimicag.2016.06.008

Karvanen, M., Plachouras, D., Friberg, L. E., Paramythiotou, E., Papadomichelakis, E., Karaiskos, I., et al. (2013). Colistin methanesulfonate and colistin pharmacokinetics in critically ill patients receiving continuous venovenous hemodiafiltration. Antimicrob Agents Chemother. 57, 668-671. doi: 10.1128/ AAC.00985-12

Kawano, S., Matsumoto, K., Hara, R., Kuroda, Y., Ikawa, K., Morikawa, N., et al. (2015). Pharmacokinetics and dosing estimation of meropenem in japanese patients receiving continuous venovenous hemodialysis. J. Infect. Chemother. 21, 476-478. doi: 10.1016/j.jiac.2015.02.011

Kesner, J. M., Yardman-Frank, J. M., Mercier, R. C., Wong, C. S., Walker, S. E., Argyres, D. P., et al. (2014). Trimethoprim and sulfamethoxazole transmembrane clearance during modeled continuous renal replacement therapy. Blood Purif 38, 195-202. doi: 10.1159/000368884

Kiser, T. H., Fish, D. N., Aquilante, C. L., Rower, J. E., Wempe, M. F., MacLaren, R., et al. (2015). Evaluation of sulfobutylether-beta-cyclodextrin (sbecd) accumulation and voriconazole pharmacokinetics in critically ill patients undergoing continuous renal replacement therapy. Crit. Care 19, 32. doi: 10.1186/s13054-015-0753-8

Kohama, H., Ide, T., Ikawa, K., Morikawa, N., and Nishi, S. (2017). Pharmacokinetics and outcome of tazobactam/piperacillin in japanese patients undergoing low-flow continuous renal replacement therapy: dosage considerations. Clin. Pharmacol. 9, 39-44. doi: 10.2147/CPAA.S127502

Kuti, J. L., Ghazi, I. M., Quintiliani, R. J., Shore, E., and Nicolau, D. P. (2016). Treatment of multidrug-resistant pseudomonas aeruginosa with ceftolozane/ tazobactam in a critically ill patient receiving continuous venovenous haemodiafiltration. Int. J. Antimicrob Agents 48, 342-343. doi: 10.1016/ j.ijantimicag.2016.06.005

Lam, S. W., and Bauer, S. R. (2013). Amikacin pharmacokinetics during continuous veno-venous hemodialysis. Infect. Dis. Ther. 2, 217-226. doi: $10.1007 / \mathrm{s} 40121-013-0012-8$

Langgartner, J., Vasold, A., Gluck, T., Reng, M., and Kees, F. (2008). Pharmacokinetics of meropenem during intermittent and continuous intravenous application in patients treated by continuous renal replacement therapy. Intensive Care Med. 34, 1091-1096. doi: 10.1007/ s00134-008-1034-7

Lemaitre, F., Luyt, C. E., Roullet-Renoleau, F., Nieszkowska, A., Zahr, N., Fernandez, C., et al. (2010). Oseltamivir carboxylate accumulation in a patient treated by haemodiafiltration and extracorporeal membrane oxygenation. Intensive Care Med. 36, 1273-1274. doi: 10.1007/s00134-0101882-9

Lemaitre, F., Luyt, C. E., Roullet-Renoleau, F., Nieszkowska, A., Zahr, N., Corvol, E., et al. (2012). Impact of extracorporeal membrane oxygenation and continuous venovenous hemodiafiltration on the pharmacokinetics of oseltamivir carboxylate in critically ill patients with pandemic (h1n1) influenza. Ther. Drug Monit 34, 171-175. doi: 10.1097/FTD.0b013e318248672c

Leuppi-Taegtmeyer, A. B., Decosterd, L., Osthoff, M., Mueller, N. J., Buclin, T., and Corti, N. (2019). Multicenter population pharmacokinetic study of colistimethate sodium and colistin dosed as in normal renal function in patients on continuous renal replacement therapy. Antimicrob Agents Chemother. 63, e1918-e1957. doi: 10.1128/AAC.01957-18

Li, S., and Xie, F. (2019). Population pharmacokinetics and simulations of imipenem in critically ill patients undergoing continuous renal replacement therapy. Int. J. Antimicrob Agents 53, 98-105. doi: 10.1016/j.ijantimicag. 2018.10.006

Li, J., Rayner, C. R., Nation, R. L., Deans, R., Boots, R., Widdecombe, N., et al. (2005). Pharmacokinetics of colistin methanesulfonate and colistin in a critically ill patient receiving continuous venovenous hemodiafiltration. Antimicrob Agents Chemother. 49, 4814-4815. doi: 10.1128/AAC.49.11.4814-4815.2005

Li, Q., Liang, F., Sang, L., Li, P., Lv, B., Tan, L., et al. (2020). Pharmacokinetics of and maintenance dose recommendations for vancomycin in severe pneumonia patients undergoing continuous venovenous hemofiltration with the combination of predilution and postdilution. Eur. J. Clin. Pharmacol. 76, 211-217. doi: 10.1007/s00228-019-02755-5

Lopez, N. D., and Phillips, K. M. (2014). Fluconazole pharmacokinetics in a morbidly obese, critically ill patient receiving continuous venovenous hemofiltration. Pharmacotherapy 34, e162-e168. doi: 10.1002/phar.1470 
Macedo, E., and Mehta, R. L. (2016). Continuous dialysis therapies: core curriculum 2016. Am. J. Kidney Dis. 68, 645-657. doi: 10.1053/ j.ajkd.2016.03.427

Mahmoud, A., Shah, A., Nutley, K., Nicolau, D. P., Sutherland, C., Jain, M., et al. (2020). Clinical pharmacokinetics of ceftolozane and tazobactam in an obese patient receiving continuous venovenous haemodiafiltration: a patient case and literature review. J. Glob Antimicrob Resist. 21, 83-85. doi: 10.1016/ j.jgar.2020.03.003

Malone, R. S., Fish, D. N., Abraham, E., and Teitelbaum, I. (2001). Pharmacokinetics of levofloxacin and ciprofloxacin during continuous renal replacement therapy in critically ill patients. Antimicrob Agents Chemother. 45, 2949-2954. doi: 10.1128/AAC.45.10.2949-2954.2001

Malone, M. E., Corrigan, O. I., Kavanagh, P. V., Gowing, C., Donnelly, M., and Arcy, D. M. (2013). Pharmacokinetics of amphotericin b lipid complex in critically ill patients undergoing continuous venovenous haemodiafiltration. Int. J. Antimicrob Agents 42, 335-342. doi: 10.1016/j.ijantimicag.2013.06.011

Matsumoto, K., Takesue, Y., Ohmagari, N., Mochizuki, T., Mikamo, H., Seki, M., et al. (2013). Practice guidelines for therapeutic drug monitoring of vancomycin: a consensus review of the japanese society of chemotherapy and the japanese society of therapeutic drug monitoring. J. Infect. Chemother. 19, 365-380. doi: 10.1007/s10156-013-0599-4

McGloughlin, S., Roberts, J. A., O’Donoghue, S., Martin, J., Briscoe, S., and Lipman, J. (2011). Ganciclovir pharmacokinetics and suggested dosing in continuous venovenous haemodiafiltration. Int. J. Antimicrob Agents 37, 9092. doi: 10.1016/j.ijantimicag.2010.10.003

Menna, P., Salvatorelli, E., Mattei, A., Cappiello, D., Minotti, G., and Carassiti, M. (2018). Modified colistin regimen for critically ill patients with acute renal impairment and continuous renal replacement therapy. Chemotherapy 63, 3538. doi: 10.1159/000484974

Meyer, B., Ahmed, E. G. S., Delle, K. G., Locker, G. J., Heinz, G., Jaeger, W., et al. (2003). How to calculate clearance of highly protein-bound drugs during continuous venovenous hemofiltration demonstrated with flucloxacillin. Kidney Blood Press Res. 26, 135-140. doi: 10.1159/000070997

Michikoshi, J., Matsumoto, S., Miyawaki, H., Morita, M., Niu, H., Seo, K., et al. (2019). Evaluation of proteins and cells that adsorb to dialysis membranes used in continuous hemodiafiltration: comparison of an69st, polymethylmethacrylate, and polysulfone membranes. Blood Purif 48, 358367. doi: 10.1159/000501632

Mueller, M., de la Pena, A., and Derendorf, H. (2004). Issues in pharmacokinetics and pharmacodynamics of anti-infective agents: kill curves versus mic. Antimicrob Agents Chemother. 48, 369-377. doi: 10.1128/aac.48.2.369377.2004

Nowak-Kozka, I., Polok, K. J., Gorka, J., Fronczek, J., Gielicz, A., Seczyńska, B., et al. (2020). Concentration of meropenem in patients with sepsis and acute kidney injury before and after initiation of continuous renal replacement therapy: a prospective observational trial. Pharmacol. Rep. 72, 147-155. doi: 10.1007/s43440-019-00056-3

Ohchi, Y., Hidaka, S., Goto, K., Shitomi, R., Nishida, T., Abe, T., et al. (2011). Effect of hemopurification rate on doripenem pharmacokinetics in critically ill patients receiving high-flow continuous hemodiafiltration. Yakugaku Zasshi 131, 1395-1399. doi: 10.1248/yakushi.131.1395

Oliver, W. D., Heil, E. L., Gonzales, J. P., Mehrotra, S., Robinett, K., Saleeb, P., et al. (2015). Ceftolozane-tazobactam pharmacokinetics in a critically ill patient on continuous venovenous hemofiltration. Antimicrob Agents Chemother. 60, 1899-1901. doi: 10.1128/AAC.02608-15

Omrani, A. S., Mously, A., Cabaluna, M. P., Kawas, J., Albarrak, M. M., Alfahad, W. A., et al. (2015). Vancomycin therapy in critically ill patients on continuous renal replacement therapy; Are we doing enough? Saudi Pharm. J. 23, 327-329. doi: $10.1016 /$ j.jsps.2014.08.005

Onichimowski, D., Ziolkowski, H., Nosek, K., Jaroszewski, J., Rypulak, E., and Czuczwar, M. (2020a). Comparison of adsorption of selected antibiotics on the filters in continuous renal replacement therapy circuits: in vitro studies. J. Artif. Organs. 23, 163-170. doi: 10.1007/s10047-019-01139-x

Onichimowski, D., Bedzkowska, A., Ziolkowski, H., Jaroszewski, J., Borys, M., Czuczwar, M., et al. (2020b). Population pharmacokinetics of standard-dose meropenem in critically ill patients on continuous renal replacement therapy: a prospective observational trial. Pharmacol. Rep. [Online ahead of print]. doi: $10.1007 /$ s43440-020-00104-3
Oualha, M., Treluyer, J. M., Moshous, D., Bougnoux, M. E., Starck, J., Renolleau, S., et al. (2019). Fluconazole exposure in plasma and bile during continuous venovenous hemodialysis. Ther. Drug Monit 41, 544-546. doi: 10.1097/ FTD.0000000000000641

Palevsky, P. M., Liu, K. D., Brophy, P. D., Chawla, L. S., Parikh, C. R., Thakar, C. V., et al. (2013). Kdoqi us commentary on the $2012 \mathrm{kdigo}$ clinical practice guideline for acute kidney injury. Am. J. Kidney Dis. 61, 649-672. doi: 10.1053/ j.ajkd.2013.02.349

Patel, K., Roberts, J. A., Lipman, J., Tett, S. E., Deldot, M. E., and Kirkpatrick, C. M. (2011). Population pharmacokinetics of fluconazole in critically ill patients receiving continuous venovenous hemodiafiltration: using monte carlo simulations to predict doses for specified pharmacodynamic targets. Antimicrob Agents Chemother. 55, 5868-5873. doi: 10.1128/AAC.00424-11

Pea, F., Viale, P., Pavan, F., and Furlanut, M. (2007). Pharmacokinetic considerations for antimicrobial therapy in patients receiving renal replacement therapy. Clin. Pharmacokinet 46, 997-1038. doi: 10.2165/ 00003088-200746120-00003

Philpott, C. D., Droege, C. A., Droege, M. E., Healy, D. P., Courter, J. D., Ernst, N. E., et al. (2019). Pharmacokinetics and pharmacodynamics of extended-infusion cefepime in critically ill patients receiving continuous renal replacement therapy: a prospective, open-label study. Pharmacotherapy 39, 1066-1076. doi: 10.1002/ phar.2332

Pistolesi, V., Morabito, S., Di Mario, F., Regolisti, G., Cantarelli, C., and Fiaccadori, E. (2019). A guide to understanding antimicrobial drug dosing in critically ill patients on renal replacement therapy. Antimicrob Agents Chemother. 63, e519-e583. doi: 10.1128/AAC.00583-19

Preiswerk, B., Rudiger, A., Fehr, J., and Corti, N. (2013). Experience with daptomycin daily dosing in icu patients undergoing continuous renal replacement therapy. Infection 41, 553-557. doi: 10.1007/s15010-012-0300-3

Richter, D. C., Frey, O., Rohr, A., Roberts, J. A., Köberer, A., Fuchs, T., et al. (2019). Therapeutic drug monitoring-guided continuous infusion of piperacillin/ tazobactam significantly improves pharmacokinetic target attainment in critically ill patients: a retrospective analysis of four years of clinical experience. Infection 47, 1001-1011. doi: 10.1007/s15010-019-01352-Z

Roberts, D. M., Roberts, J. A., Roberts, M. S., Liu, X., Nair, P., Cole, L., et al. (2012). Variability of antibiotic concentrations in critically ill patients receiving continuous renal replacement therapy: a multicentre pharmacokinetic study. Crit. Care Med. 40, 1523-1528. doi: 10.1097/CCM.0b013e318241e553

Roberts, J. A., Udy, A. A., Bulitta, J. B., Stuart, J., Jarrett, P., Starr, T., et al. (2014). Doripenem population pharmacokinetics and dosing requirements for critically ill patients receiving continuous venovenous haemodiafiltration. J. Antimicrob Chemother. 69, 2508-2516. doi: 10.1093/jac/dku177

Roberts, D. M., Liu, X., Roberts, J. A., Nair, P., Cole, L., Roberts, M. S., et al. (2015). A multicenter study on the effect of continuous hemodiafiltration intensity on antibiotic pharmacokinetics. Crit. Care 19, 84. doi: 10.1186/s13054-015-0818-8

Roberts, J. A., Joynt, G., Lee, A., Choi, G., Bellomo, R., Kanji, S., et al. (2020). The effect of renal replacement therapy and antibiotic dose on antibiotic concentrations in critically ill patients: data from the multinational smarrt study. Clin. Infect. Dis. [Online ahead of print]. doi: 10.1093/cid/ciaa224

Roehr, A. C., Frey, O. R., Koeberer, A., Fuchs, T., Roberts, J. A., and Brinkmann, A. (2015). Anti-infective drugs during continuous hemodialysis - using the bench to learn what to do at the bedside. Int. J. Artif. Organs 38, 17-22. doi: 10.5301/ ijao. 5000377

Roger, C., Wallis, S. C., Louart, B., Lefrant, J. Y., Lipman, J., Muller, L., et al. (2016a). Comparison of equal doses of continuous venovenous haemofiltration and haemodiafiltration on ciprofloxacin population pharmacokinetics in critically ill patients. J. Antimicrob Chemother. 71, 1643-1650. doi: 10.1093/ jac/dkw043

Roger, C., Wallis, S. C., Muller, L., Saissi, G., Lipman, J., Lefrant, J., et al. (2016b). Influence of renal replacement modalities on amikacin population pharmacokinetics in critically ill patients on continuous renal replacement therapy. Antimicrob Agents Chemother. 60, 4901-4909. doi: 10.1128/ AAC.00828-16

Roger, C., Cotta, M. O., Muller, L., Wallis, S. C., Lipman, J., Lefrant, J., et al. (2017a). Impact of renal replacement modalities on the clearance of piperacillin-tazobactam administered via continuous infusion in critically ill patients. Int. J. Antimicrob Agents 50, 227-231. doi: 10.1016/j.ijantimicag. 2017.03.018 
Roger, C., Wallis, S. C., Muller, L., Saissi, G., Lipman, J., Brüggemann, R., J., et al. (2017b). Caspofungin population pharmacokinetics in critically ill patients undergoing continuous veno-venous haemofiltration or haemodiafiltration. Clin. Pharmacokinet 56, 1057-1068. doi: 10.1007/s40262-016-0495-Z

Scheetz, M. H., Griffith, M. M., Ghossein, C., Hollister, A. S., and Ison, M. G. (2011). Pharmacokinetic assessment of peramivir in a hospitalized adult undergoing continuous venovenous hemofiltration. Ann. Pharmacother. 45, e64. doi: 10.1345/aph.1Q437

Seyler, L., Cotton, F., Taccone, F. S., De Backer, D., Macours, P., Vincent, J., et al. (2011). Recommended beta-lactam regimens are inadequate in septic patients treated with continuous renal replacement therapy. Crit. Care 15, R137. doi: $10.1186 / \mathrm{cc} 10257$

Shaw, A. R., and Mueller, B. A. (2017). Antibiotic dosing in continuous renal replacement therapy. Adv. Chronic Kidney Dis. 24, 219-227. doi: 10.1053/ j.ackd.2017.05.004

Shotwell, M. S., Nesbitt, R., Madonia, P. N., Gould, E. R., Connor, M. J., Salem, C., et al. (2016). Pharmacokinetics and pharmacodynamics of extended infusion versus short infusion piperacillin-tazobactam in critically ill patients undergoing crrt. Clin. J. Am. Soc. Nephrol. 11, 1377-1383. doi: 10.2215/ CJN.10260915

Sime, F. B., Pandey, S., Karamujic, N., Parker, S., Alexander, E., Loutit, J., et al. (2018a). Ex vivo characterization of effects of renal replacement therapy modalities and settings on pharmacokinetics of meropenem and vaborbactam. Antimicrob Agents Chemother. 62. doi: 10.1128/ AAC.01306-18

Sime, F. B., Stuart, J., Butler, J., Starr, T., Wallis, S. C., Pandey, S., et al. (2018b). A pharmacokinetic case study of intravenous posaconazole in a critically ill patient with hypoalbuminaemia receiving continuous venovenous haemodiafiltration. Int. J. Antimicrob Agents 52, 506-509. doi: 10.1016/ j.ijantimicag.2018.07.008

Sime, F. B., Lassig-Smith, M., Starr, T., Stuart, J., Pandey, S., Parker, S. L., et al. (2019). A population pharmacokinetic model-guided evaluation of ceftolozane-tazobactam dosing in critically ill patients undergoing continuous venovenous hemodiafiltration. Antimicrob Agents Chemother. 64, e1619-e1655. doi: 10.1128/AAC.01655-19

Soukup, P., Faust, A. C., Edpuganti, V., Putnam, W. C., and McKinnell, J. A. (2019). Steady-state ceftazidime-avibactam serum concentrations and dosing recommendations in a critically ill patient being treated for pseudomonas aeruginosa pneumonia and undergoing continuous venovenous hemodiafiltration. Pharmacotherapy 39, 1216-1222. doi: 10.1002/phar.2338

Spapen, H., van Laethem, J., Hites, M., Verdoodt, A., Diltoer, M., and Honoré, P. M. (2019). Treatment of ventilator-associated pneumonia with high-dose colistin under continuous veno-venous hemofiltration. J. Transl. Int. Med. 7, 100-105. doi: 10.2478/jtim-2019-0022

Spooner, A. M., Deegan, C., D’Arcy, D. M., Gowing, C. M., Donnelly, M. B., and Corrigan, O. I. (2011). An evaluation of ciprofloxacin pharmacokinetics in critically ill patients undergoing continuous veno-venous haemodiafiltration. BMC Clin. Pharmacol. 11, 11. doi: 10.1186/1472-6904-11-11

Stevens, P. E., and Levin, A. (2013). Evaluation and management of chronic kidney disease: synopsis of the kidney disease: improving global outcomes 2012 clinical practice guideline. Ann. Intern Med. 158, 825-830. doi: 10.7326/ 0003-4819-158-11-201306040-00007

Stevenson, J. M., Patel, J. H., Churchwell, M. D., Vilay, A. M., Depestel, D. D., Sörgel, F., et al. (2008). Ertapenem clearance during modeled continuous renal replacement therapy. Int. J. Artif. Organs 31, 1027-1034. doi: 10.1177/ 039139880803101206

Suyama, H., Ikawa, K., Morikawa, N., Ikeda, K., Fujiue, Y., Morikawa, S., et al. (2008). Pharmacokinetics and pharmacodynamics of biapenem in critically ill patients under continuous venovenous hemodiafiltration. Jpn J. Antibiot 61, 303-313.

Taccone, F. S., de Backer, D., Laterre, P. F., Spapen, H., Dugernier, T., Delattre, I., et al. (2011). Pharmacokinetics of a loading dose of amikacin in septic patients undergoing continuous renal replacement therapy. Int. J. Antimicrob Agents 37, 531-535. doi: 10.1016/j.ijantimicag.2011.01.026

Tamme, K., Oselin, K., Kipper, K., Low, K., Standing, J. F., Metsvaht, T., et al. (2015). Pharmacokinetics of doripenem during high volume hemodiafiltration in patients with septic shock. J. Clin. Pharmacol. 55, 438-446. doi: 10.1002/ jcph.432
Tandukar, S., and Palevsky, P. M. (2019). Continuous renal replacement therapy: who, when, why, and how. Chest 155, 626-638. doi: 10.1016/ j.chest.2018.09.004

Tanoue, K., Nishi, K., Kadowaki, D., and Hirata, S. (2011). Removal of doripenem during hemodialysis and the optimum dosing regimen for patients undergoing hemodialysis. Ther. Apher Dial 15, 327-333. doi: 10.1111/j.17449987.2011.00914.x

Tokimatsu, I., Shigemura, K., Kotaki, T., Yoshikawa, H., Yamamichi, F., Tomo, T., et al. (2017). A prospective study of the efficacy, safety and pharmacokinetics of enteral moxifloxacin in the treatment of hemodialysis patients with pneumonia. Intern Med. 56, 1315-1319. doi: 10.2169/internalmedicine.56.8369

Tolwani, A. (2012). Continuous renal-replacement therapy for acute kidney injury. N Engl. J. Med. 367, 2505-2514. doi: 10.1056/NEJMct1206045

Trotman, R. L., Williamson, J. C., Shoemaker, D. M., and Salzer, W. L. (2005). Antibiotic dosing in critically ill adult patients receiving continuous renal replacement therapy. Clin. Infect. Dis. 41, 1159-1166. doi: 10.1086/444500

Tsuji, B. T., Pogue, J. M., Zavascki, A. P., Paul, M., Daikos, G. L., Forrest, A., et al. (2019). International consensus guidelines for the optimal use of the polymyxins: endorsed by the american college of clinical pharmacy (accp), european society of clinical microbiology and infectious diseases (escmid), infectious diseases society of america (idsa), international society for antiinfective pharmacology (isap), society of critical care medicine $(\mathrm{sccm})$, and society of infectious diseases pharmacists (sidp). Pharmacotherapy 39, 10-39. doi: 10.1002/phar.2209

Ulldemolins, M., Soy, D., Llaurado-Serra, M., Vaquer, S., Castro, P., Rodríguez, A. H., et al. (2015). Meropenem population pharmacokinetics in critically ill patients with septic shock and continuous renal replacement therapy: influence of residual diuresis on dose requirements. Antimicrob Agents Chemother. 59, 5520-5528. doi: 10.1128/AAC.00712-15

Ulldemolins, M., Martin-Loeches, I., Llaurado-Serra, M., Fernandez, J., Vaquer, S., Rodríguez, A., et al. (2016). Piperacillin population pharmacokinetics in critically ill patients with multiple organ dysfunction syndrome receiving continuous venovenous haemodiafiltration: effect of type of dialysis membrane on dosing requirements. J. Antimicrob Chemother. 71, 16511659. doi: $10.1093 / \mathrm{jac} / \mathrm{dkv} 503$

van de Vijsel, L. M., Walker, S. A., Walker, S. E., Yamashita, S., Simor, A., Hladunewich, M., et al. (2010). Initial vancomycin dosing recommendations for critically ill patients undergoing continuous venovenous hemodialysis. Can. J. Hosp Pharm. 63, 196-206. doi: 10.4212/cjhp.v63i3.915

Van Wert, R., Friedrich, J. O., Scales, D. C., Wald, R., and Adhikari, N. K. J. (2010). High-dose renal replacement therapy for acute kidney injury: systematic review and meta-analysis. Crit. Care Med. 38, 1360-1369. doi: 10.1097/ CCM.0b013e3181d9d912

Varghese, J. M., Jarrett, P., Wallis, S. C., Boots, R. J., Kirkpatrick, C. M., Lipman, J., et al. (2015). Are interstitial fluid concentrations of meropenem equivalent to plasma concentrations in critically ill patients receiving continuous renal replacement therapy? J. Antimicrob Chemother. 70, 528-533. doi: 10.1093/ jac/dku413

Vilay, A. M., Grio, M., Depestel, D. D., Sowinski, K. M., Gao, L., Heung, M., et al. (2011). Daptomycin pharmacokinetics in critically ill patients receiving continuous venovenous hemodialysis. Crit. Care Med. 39, 19-25. doi: 10.1097/CCM.0b013e3181fa36fb

Villa, G., Di Maggio, P., De Gaudio, A. R., Novelli, A., Antoniotti, R., Fiaccadori, E., et al. (2016). Effects of continuous renal replacement therapy on linezolid pharmacokinetic/pharmacodynamics: a systematic review. Crit. Care 20, 374. doi: 10.1186/s13054-016-1551-7

Vossen, M. G., Wenisch, J. M., Maier-Salamon, A., Fritsch, A., Saria, K., Zuba, C., et al. (2015). Doripenem treatment during continuous renal replacement therapy. Antimicrob Agents Chemother. 60, 1687-1694. doi: 10.1128/ AAC.01801-15

Vossen, M. G., Knafl, D., Haidinger, M., Lemmerer, R., Unger, M., Pferschy, S., et al. (2017). Micafungin plasma levels are not affected by continuous renal replacement therapy: experience in critically ill patients. Antimicrob Agents Chemother. 61, e2416-e2425. doi: 10.1128/AAC.02425-16

Wallis, S. C., Mullany, D. V., Lipman, J., Rickard, C. M., and Daley, P. J. (2001). Pharmacokinetics of ciprofloxacin in icu patients on continuous veno-venous haemodiafiltration. Intensive Care Med. 27, 665-672. doi: 10.1007/ s001340100857 
Weiler, S., Seger, C., Pfisterer, H., Stienecke, E., Stippler, F., Welte, R., et al. (2013). Pharmacokinetics of caspofungin in critically ill patients on continuous renal replacement therapy. Antimicrob Agents Chemother. 57, 4053-4057. doi: 10.1128/AAC.00335-13

Wenzler, E., Bunnell, K. L., Bleasdale, S. C., Benken, S., Danziger, L. H., and Rodvold, K. A. (2017). Pharmacokinetics and dialytic clearance of ceftazidimeavibactam in a critically ill patient on continuous venovenous hemofiltration. Antimicrob Agents Chemother. 61, e417-e464. doi: 10.1128/AAC.00464-17

Wolter, K., Claus, M., and Fritschka, E. (1994). Pharmacokinetics and dosage recommendations of teicoplanin in patients treated by continuous venovenous haemodialysis (cvvhd). Eur. J. Clin. Pharmacol. 46, 179-180. doi: 10.1007/bf00199886

Wong, W. T., Choi, G., Gomersall, C. D., and Lipman, J. (2015). To increase or decrease dosage of antimicrobials in septic patients during continuous renal replacement therapy: the eternal doubt. Curr. Opin. Pharmacol. 24, 68-78. doi: 10.1016/j.coph.2015.07.003

Xie, F., Li, S., and Cheng, Z. (2020). Population pharmacokinetics and dosing considerations of daptomycin in critically ill patients undergoing continuous renal replacement therapy. J. Antimicrob Chemother. 75, 1559-1566. doi: $10.1093 / \mathrm{jac} / \mathrm{dkaa} 028$
Xu, X., Khadzhynov, D., Peters, H., Chaves, R. L., Hamed, K., Levi, M., et al. (2017). Population pharmacokinetics of daptomycin in adult patients undergoing continuous renal replacement therapy. Br. J. Clin. Pharmacol. 83, 498-509. doi: 10.1111/bcp.13131

Yagasaki, K., Gando, S., Matsuda, N., Kameue, T., Ishitani, T., Hirano, T., et al. (2003). Pharmacokinetics of teicoplanin in critically ill patients undergoing continuous hemodiafiltration. Intensive Care Med. 29, 2094-2095. doi: 10.1007/s00134-003-1914-9

Conflict of Interest: The authors declare that the research was conducted in the absence of any commercial or financial relationships that could be construed as a potential conflict of interest.

Copyright (c) $2020 \mathrm{Li}, \mathrm{Li}, \mathrm{Xia}$, Chu, Zhong, Li, Liang, Bu, Zhao, Liao, Yang, Lu and Jiang. This is an open-access article distributed under the terms of the Creative Commons Attribution License (CC BY). The use, distribution or reproduction in other forums is permitted, provided the original author(s) and the copyright owner(s) are credited and that the original publication in this journal is cited, in accordance with accepted academic practice. No use, distribution or reproduction is permitted which does not comply with these terms. 